\title{
Inhibition of PI3K signalling increases the efficiency of radiotherapy in glioblastoma cells
}

\author{
SEBASTIAN HASSLACHER ${ }^{1,6^{*}}$, LUKAS SCHNEELE ${ }^{1 *}$, SEBASTIEN STROH $^{1,7}$, JULIA LANGHANS ${ }^{1}$, \\ KATHARINA ZEILER ${ }^{1,2}$, PATRICIA KATTNER ${ }^{1}$, GEORG KARPEL-MASSLER ${ }^{2,3}$, MARKUS D. SIEGELIN ${ }^{3}$, \\ MATTHIAS SCHNEIDER ${ }^{1,2,8}$, SHAOXIA ZHOU ${ }^{4}$, MICHAEL GRUNERT $^{5}$, MARC-ERIC HALATSCH ${ }^{2}$, \\ LISA NONNENMACHER $^{1 * *}$, KLAUS-MICHAEL DEBATIN $^{1 * *}$ and MIKE-ANDREW WESTHOFF ${ }^{1 * *}$ \\ Departments of ${ }^{1}$ Pediatrics and Adolescent Medicine, and ${ }^{2}$ Neurosurgery, University Medical Center Ulm, \\ D-89075 Ulm, Germany; ${ }^{3}$ Department of Pathology and Cell Biology, Columbia University Medical Center, \\ New York, NY 10032, USA; ${ }^{4}$ Department of Clinical Chemistry, University Medical Center Ulm, D-89075 Ulm; \\ ${ }^{5}$ Department of Radiology, German Armed Forces Hospital of Ulm, D-89081 Ulm, Germany
}

Received March 8, 2018; Accepted July 20, 2018

DOI: $10.3892 /$ ijo.2018.4528

\begin{abstract}
Glioblastoma, the most common primary brain tumour, is also considered one of the most lethal cancers per se. It is highly refractory to therapeutic intervention, as highlighted by the mean patient survival of only 15 months, despite an aggressive treatment approach, consisting of maximal safe surgical resection, followed by radio- and chemotherapy. Radiotherapy, in particular, can have effects on the surviving fractions of tumour cells, which are considered adverse to the desired clinical outcome: It can induce increased cellular proliferation, as well as enhanced invasion. In this study, we established that differentiated glioblastoma cells alter their DNA repair response following repeated exposure to radiation and, therefore, high single-dose irradiation (SD-IR) is not a good surrogate marker for fractionated dose irradiation (FD-IR), as used in clinical practice. Integrating irradiation into a combination therapy approach, we then investigated whether the pharmacological inhibition of PI3K signalling, the most abundantly activated survival cascade in glioblastoma, enhances the efficacy of radiotherapy. Of
\end{abstract}

Correspondence to: Dr Mike-Andrew Westhoff, Department of Pediatrics and Adolescent Medicine, University Medical Center Ulm, Eythstrasse 24, D-89075 Ulm, Germany

E-mail: andrew.westhoff@uniklinik-ulm.de

Present addresses: ${ }^{6}$ Department of Internal Medicine, Stadtspital Triemli, 8063 Zurich, Switzerland; ${ }^{7}$ Department of Neurology, University Medical Center Ulm, D-89075 Ulm; ${ }^{8}$ Department of Neurosurgery, Rheinische Friedrich Wilhelms University Hospital, D-53113 Bonn, Germany

*Contributed equally

${ }^{* *}$ Shared senior authorship

Key words: apoptosis, motility/invasion, radiotherapy, glioblastoma, PI3K, GDC-0941 note, treatment with GDC-0941, which blocks PI3K-mediated signalling, did not enhance cell death upon irradiation, but both treatment modalities functioned synergistically to reduce the total cell number. Furthermore, GDC-0941 not only prevented the radiation-induced increase in the motility of the differentiated cells, but further reduced their speed below that of untreated cells. Therefore, combining radiotherapy with the pharmacological inhibition of PI3K signalling is a potentially promising approach for the treatment of glioblastoma, as it can reduce the unwanted effects on the surviving fraction of tumour cells.

\section{Introduction}

Over $65 \%$ of all malignant primary brain tumours are glioblastoma, formerly also referred to as glioblastoma multiforme (1). While this highly aggressive tumour only rarely metastasises outside the neuroaxis $(2,3)$, intracranially invading, single tumour cells can be found up to $6 \mathrm{~cm}$ from the tumour bulk (4), thus rendering complete surgical resection unachievable. The two-fold surgical reality of glioblastoma treatment has been formulated as follows: The greater the extent of surgical tumour removal, the longer the patient survival and, regardless the extent of removal, recurrence is inevitable (5). Therefore, the current standard treatment consists of a three-prong approach: Maximal safe surgical removal, radiotherapy and treatment with the chemotherapeutic agent, temozolomide (6). Nevertheless, mean patient survival is only approximately one year after diagnosis (7).

Further improvements in therapy are considered difficult, as there is little additional scope for surgical excision, limited access though the blood-brain barrier for chemotherapeutic drugs and high resistance within the tumour to radiation (8). The latter aspect in particular has led to an ongoing debate about optimal fractionation schedules and doses (9), since lowdose irradiation can be sublethal in a radioresistant tumour, and side-effects, such as enhanced cell migration, which promotes tumour spread, have been shown to occur $(10,11)$. On the other 
hand, clinical trials for hypofractionated irradiation have suggested a greater risk for brain necrosis, or with adjusted doses only a limited improvement in overall survival $(12,13)$.

The PI3K survival cascade is one of the few consistently altered signalling pathways found in glioblastoma: The amplification of epidermal growth factor receptor (EGFR) (45\%), gain of function in the PI3K catalytic subunit $\alpha(15 \%)$ and loss of phosphatase and tensin homolog (PTEN) (36\%), result in an aberrant activation of this signalling cascade in approximately $88 \%$ of all tumours investigated $(14,15)$. Importantly, unlike for example in Hodgkin's lymphoma (16), PI3K-mediated signalling does not appear essential for the survival of glioblastoma cells. It is therefore likely that the role of this signalling cascade is highly complex (17). A fact which is also reflected in the failure to successfully integrate pharmacological inhibitors into a clinical setting, to date, only two modulators of PI3Kmediated signalling, everolimus and temsirolimus, have been clinically approved for glioblastoma treatment (18). Our own recent study further demonstrates that modulating the PI3K pathway in glioblastoma cell lines and differentiated cells (DCs) can significantly inhibit their locomotive properties (19). A recent, more detailed analysis revealed differential roles of the PI3K pathway in glioblastoma stem cell-like cells (SCs) and their differentiated progeny: While the chemoresistance of SCs can be reduced to the level of the DCs, no further sensitization can be achieved in either population, i.e. PI3K-mediating signalling is responsible for the additional chemoresistance of SCs, but does not mediate resistance per se (20). By contrast, blocking PI3K signalling affects, as we have previously demonstrated (19), the motility of the DCs, but not that of the SCs (20). These findings suggest that one signalling cascade can have different functions in a single tumour, depending on the cell populations studied within the tumour.

In this study, we investigated the effects of radiation and the different modes to apply it, high single-dose irradiation (SD-IR) or fractionated dose irradiation (FD-IR) on DCs, which make up the tumour bulk and focus on the interaction between radiotherapy and the application of GDC-0941, a pharmacological inhibitor of PI3K.

\section{Materials and methods}

Cell culture. Primary Glioblastoma SCs were isolated by mechanical disaggregation from surgical specimens obtained from three patients with WHO IV glioma (G35, G38 and G40) after obtaining written informed consent as previously described (21). SCs were cultured in DMEM/F-12 (HAM) medium (Gibco; Thermo Fisher Scientific, Waltham, MA, USA), supplemented with epidermal growth factor (EGF; Biomol GmbH, Hamburg, Germany), fibroblast growth factor (FGF; Miltenyi Biotec GmbH, Bergisch Gladbach, Germany) and B27 (Gibco; Thermo FisherScientific) and induced to adhere to collagen (BD Biosciences, Bedford, MA, USA)-coated cell culture flaks/dishes. The cells were allowed to differentiate by letting them adhere to uncoated cell culture material in the presence of DMEM, supplemented with $10 \%$ FCS and penicillin/streptomycin (all from Gibco; Thermo Fisher Scientific). DC populations were maintained for $<10$ weeks. This study was approved by the Ethics Committee, Medical Faculty, Ulm University (Ulm, Germany).
Inhibitor and radiation source. The PI3K inhibitor, GDC-0941, was obtained from Selleckchem, Munich, Germany. The irradiation device used (HWM D400) was from Wälischmiller Engineering GmbH (Markdorf, Germany).

Determination of the survival fraction following 2 Gy irradiation (SF2). The SF2 value for the G35DC cells was extrapolated from the data presented in Fig. 1B, while the values for the additional cell populations were obtained from peer-reviewed literature (references provided in Table I). Whenever possible comparative analyses were selected.

Cell cycle distribution and apoptosis. The cellular DNA content was assessed by fluorescence-activated cell-sorting (FACScan; Becton Dickinson, Heidelberg, Germany) analysis of propidium iodide-stained nuclei as previously described (22).

Changes in cell number. The cells were counted using CASY1 DT (Roche Diagnostics, Indianapolis, IN, USA), as previously described (21).

Wound healing assay. Semi-directed migration was investigated using a wound healing assay. Irradiated or non-irradiated cells were seeded at a density of $5.32 \times 10^{4}$ cells $/ \mathrm{cm}^{2}$ per well of a 12 -well plate in a total volume of $1.5 \mathrm{ml}$ of medium. Following overnight incubation, the cells were treated with $0.6 \mu \mathrm{M}$ GDC-0941 and incubated for an additional $30 \mathrm{~min}$ at $37^{\circ} \mathrm{C}$. A scratch was introduced into the cell layer using a $10 \mu \mathrm{l}$ pipette tip and the plate was placed into an enclosed incubator connected to a CK40 microscope (Olympus, Hamburg, Germany). Images were acquired every $20 \mathrm{~min}$ for $24 \mathrm{~h}$ with a CAMEDIA C-4040ZOOM digital camera (Olympus).

Random motility. The random movement of the cells was analysed via time-lapse photography, as previously described (22), and an image was acquired every 20 min over a time course of $24 \mathrm{~h}$. The relative speed of the cells was quantified using ImageJ software Version 1.46r (Rasband, W.S., ImageJ; http://imagej. nih.gov/ij/, 1997-2011).

Colony formation assay. A total of 1,000 cells were seeded on $12.5 \mathrm{~cm}^{2}$ culture flasks and allowed to adhere overnight. At 10 or 11 days following treatment, the cells were washed with PBS and fixed in 3,7\% paraformaldehyde for $10 \mathrm{~min}$ and stained with 1:10 Giemsa solution for $10 \mathrm{~min}$. After several washes, colonies with $>10$ cells per colony were counted. Cell survival was calculated as a percentage of the control and mathematical interpolation was calculated with MATLAB on the basis of the linear quadratic model (23).

Immunofluorescent assessment of DNA damage. DNA damage was assessed by $\mathrm{yH} 2 \mathrm{AX}$ staining, as previously described (24).

Western blot analysis. Western blot analysis was performed as previously described (21): The cells were incubated with $20 \mu \mathrm{l}$ of lysis buffer (30 mM Tris-HCl, pH 7.5; $150 \mathrm{mM} \mathrm{NaCl}$; $1 \%$ Triton X-100; $10 \%$ Glycerol, one tablet Protease inhibitor cocktail (Roche, Mannheim, Germany) for every $50 \mathrm{ml}$ lysis buffer) for $15 \mathrm{~min}$ on ice and afterwards scraped from the dishes. Cell lysates were collected in $1.5 \mathrm{ml}$ tubes and 
A

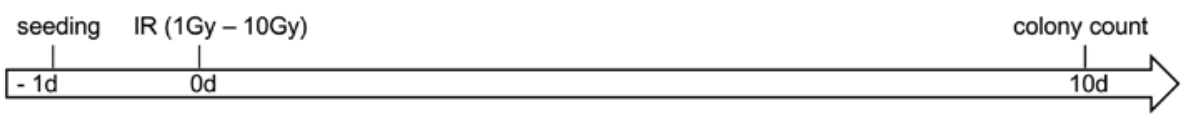

B

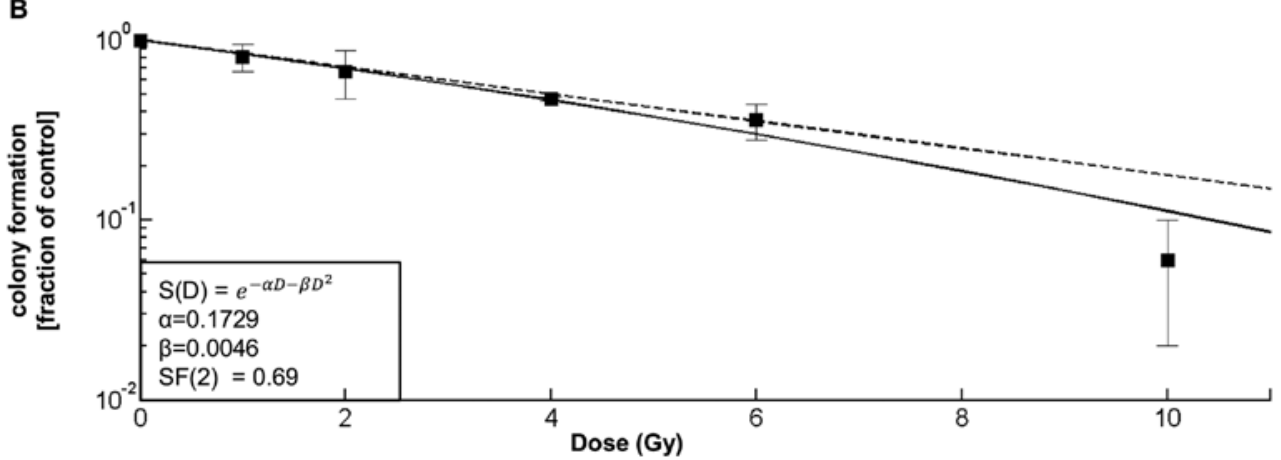

Figure 1. Determining and contrasting the SF-2 value of a glioblastoma differentiated cell (DC) population. (A) Experimental chronology: Cells were irradiated from 1-10 Gy. After 10 days, the cells were stained and colony numbers were determined. (B) Cell survival curve for irradiated G35 DC populations: The solid line shows the interpolation according to the linear quadratic model; the dotted line displays the linear part of the equation. The survival fraction at $2 \mathrm{~Gy}(\mathrm{SF} 2)$ is $\mathrm{D}(2)=0.69$. Depicted in $(\mathrm{B})$ are the means $\pm \mathrm{SD}$ of three independent experiments performed in triplicate.

centrifuged at $13,000 \mathrm{rpm}$ for $20 \mathrm{~min}$ at $4^{\circ} \mathrm{C}$. The supernatants were collected in new $1.5 \mathrm{ml}$ tubes and frozen at $-20^{\circ} \mathrm{C}$. For the determination of the protein concentration a Pierce bicinchoninic acid assay (BCA) Protein Assay Reagent kit (Thermo Scientific, Schwerte, Germany) was utilized. An amount of $50 \mu \mathrm{g}$ of protein was mixed with $6 \mathrm{X}$ loading buffer and filled up with water to equal final volumes. Samples were denatured at $95^{\circ} \mathrm{C}$ for $5 \mathrm{~min}$, placed shortly on ice, spun down and loaded on a $12 \%$ SDS gel. Following transfer onto a nitrocellulose membrane, the membrane was blocked in 5\% milk for $1 \mathrm{~h}$ on a shaker, washed three times with PBST and incubated with $15 \mathrm{ml}$ primary antibody solution at $4^{\circ} \mathrm{C}$ overnight under constant agitation. The membrane was then washed three times with PBST and incubated with the secondary antibody, freshly diluted in 5\% milk, for $1 \mathrm{~h}$ at room temperature under agitation. Washing was performed three times with PBST. Proteins were visualized by the in Pierce ECL Western Blotting Substrate kit (Thermo Scientific, Rockford, IL, USA) and chemiluminescence was captured by an autoradiography hyperfilm with an Optimax Developer. The following antibodies were used: Rabbit anti-phospho-AKT (Thr308) (1:1,000; \#4056), rabbit anti-phospho-AKT (Ser473) (1:1,000; \#9271) (both from Cell Signaling Technology, Leiden, The Netherlands), mouse anti-AKT antibody (1:1,000; \#610860; BD Biosciences), $\beta$-actin (1:20,000; \#A5441; Sigma-Aldrich, Hamburg, Germany) followed by goat antimouse IgG (\#sc-2005) or goat anti-rabbit IgG (\#sc-2004) conjugated to horseradish peroxidase (1:5,000; Santa Cruz Biotechnology, Heidelberg, Germany).

Transwell assay. Cell invasion was examined by a modified transmembrane migration (Transwell ${ }^{\circledR}$ ) assay. A total of $3 \times 10^{4}$ cells were seeded in serum-free DMEM onto collagencoated Transwell ${ }^{\circledR}$ membranes (Corning Inc., Corning, New York, NY, USA) with a pore size of $8 \mu \mathrm{m}$. For the coating and closure of the pores, collagen type I (BD Biosciences) was used; $10 \%$ FCS in the lower chamber served as an attractant. After $24 \mathrm{~h}$, the upper side of the membrane was wiped and washed three times with phosphate-buffered saline. The cells on the bottom side of the membrane were then fixed with 3.7\% paraformaldehyde and stained with 4'6-diamidino-2-phenylindole (DAPI) prior to mounting. DAPI was procured from Roche Diagnostics. The number of migrated cells was determined by analysis using a Keyence BZ-9000 microscope (Keyence Deutschland GmbH, Neu-Isenburg, Germany).

Statistical analysis. Statistical analysis was carried out by a two-sided Student's t-test for two-group comparisons and by one-way ANOVA, followed by a Bonferroni post-hoc test for multiple group comparisons. The expected response to combination treatment was calculated as fractional response to GDC-0941 (Fa) + fractional response to irradiation (Fb) $(\mathrm{Fa} \times \mathrm{Fb})$. Bliss analysis was conducted to detect synergistic (ratio of the actual total response and the expected total response $<0.9$ ), additive (this quotient equalled 0.9 to 1.1 ), or antagonistic effects (quotient $>1.1$ ). Bliss analysis was not conducted if GDC-0941 had a reverse effect compared to irradiation alone.

\section{Results}

Characterising the response of differentiated glioblastoma cells to irradiation. While DCs make up the bulk of a tumour, SCs were long held to be responsible for the characteristic features of glioblastoma, including increased resistance to radiotherapy (25). However, with the unidirectional association between the glioblastoma SC and DC population recently thrown into doubt (26), as well as the increasing doubt about the general veracity of glioblastoma SCs being more resistant to therapy than DCs (27), in this study, we first investigated the response of DCs to increasing concentrations of gamma radiation (Fig. 1A) and calculated the SF2 value (Fig. 1B). Compared to established glioblastoma cell lines, G35 DCs display a similarly high radioresistance (Table I).

We then investigated whether SD-IR is a good surrogate for repeated i.e., FD-IR, comparing 10 Gy SD-IR with 2 Gy FD-IR consecutively at 5 days per week, reflecting the 
Table I. Values for the additional cell populations obtained from peer-reviewed literature.

\begin{tabular}{lclrr}
\hline Cell Line & Refs & \multicolumn{1}{c}{ Origin of cells } & Malignancy & SF2 \\
\hline U87-MG & $(28)$ & Glioblastoma & Yes & 0.81 \\
A172 & $(29)$ & Glioblastoma & Yes & 0.74 \\
U138-MG & $(29)$ & Glioblastoma & Yes & 0.72 \\
T98G & $(30)$ & Glioblastoma & Yes & 0.70 \\
G35DC & n/a & Glwioblastoma & Yes & 0.69 \\
HeLa & $(31)$ & Cervical adenocarcinoma & Yes & 0.41 \\
SCC61 & $(28)$ & Head and neck squamous-cell carcinoma & Yes & 0.36 \\
U-622CG & $(32)$ & Glia & No & 0.25 \\
HF19 & $(33)$ & Fibroblast & & 0.20 \\
\hline
\end{tabular}

A seeding $\quad 1^{\text {st }} I R \quad 2^{\text {nd }} I R \quad 3^{\text {rd }} I R \quad 4^{\text {th }} I R \quad 5^{\text {th }}$ IR $\quad 1^{\text {st }}$ measurement $2^{\text {nd }}$ measurement $3^{\text {rd }}$ measurement

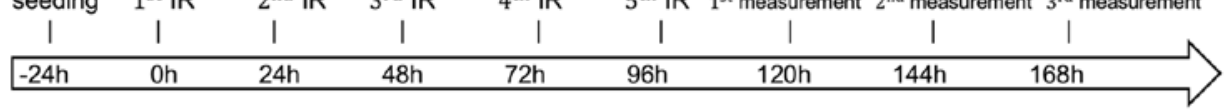

$\left.\begin{array}{rrllll}1 \times 10 \mathrm{~Gy}: & 10 \mathrm{~Gy} & - & - & - & - \\ 5 \times 2 \mathrm{~Gy}: & 2 \mathrm{~Gy} & 2 \mathrm{~Gy} & 2 \mathrm{~Gy} & 2 \mathrm{~Gy} & 2 \mathrm{~Gy}\end{array}\right\}$ total dose: $10 \mathrm{~Gy}$

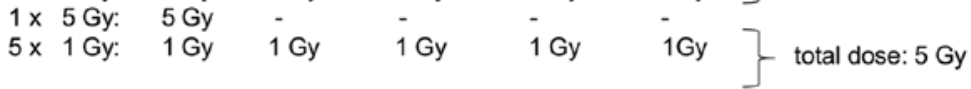
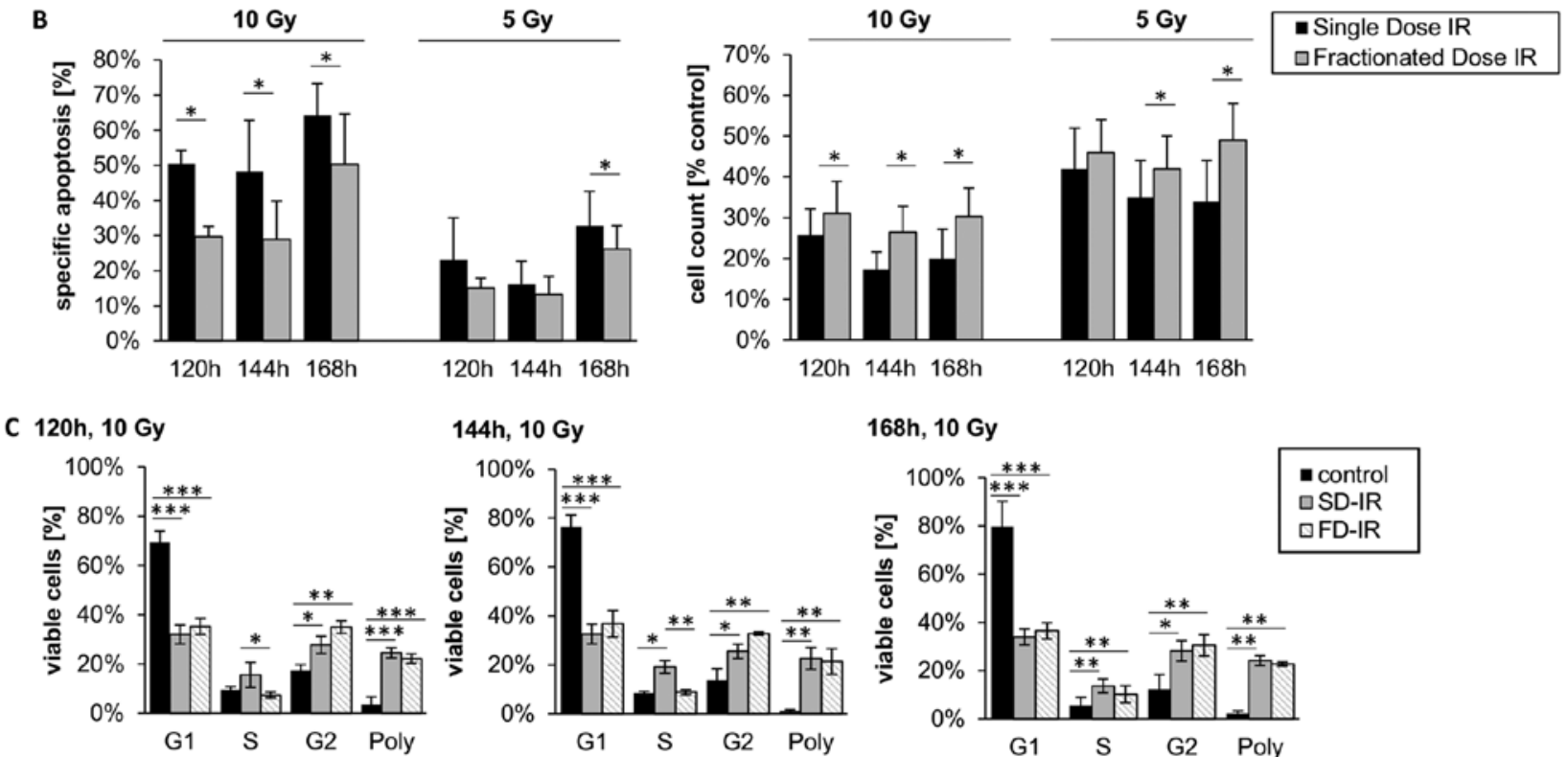

$168 \mathrm{~h}, 10 \mathrm{~Gy}$
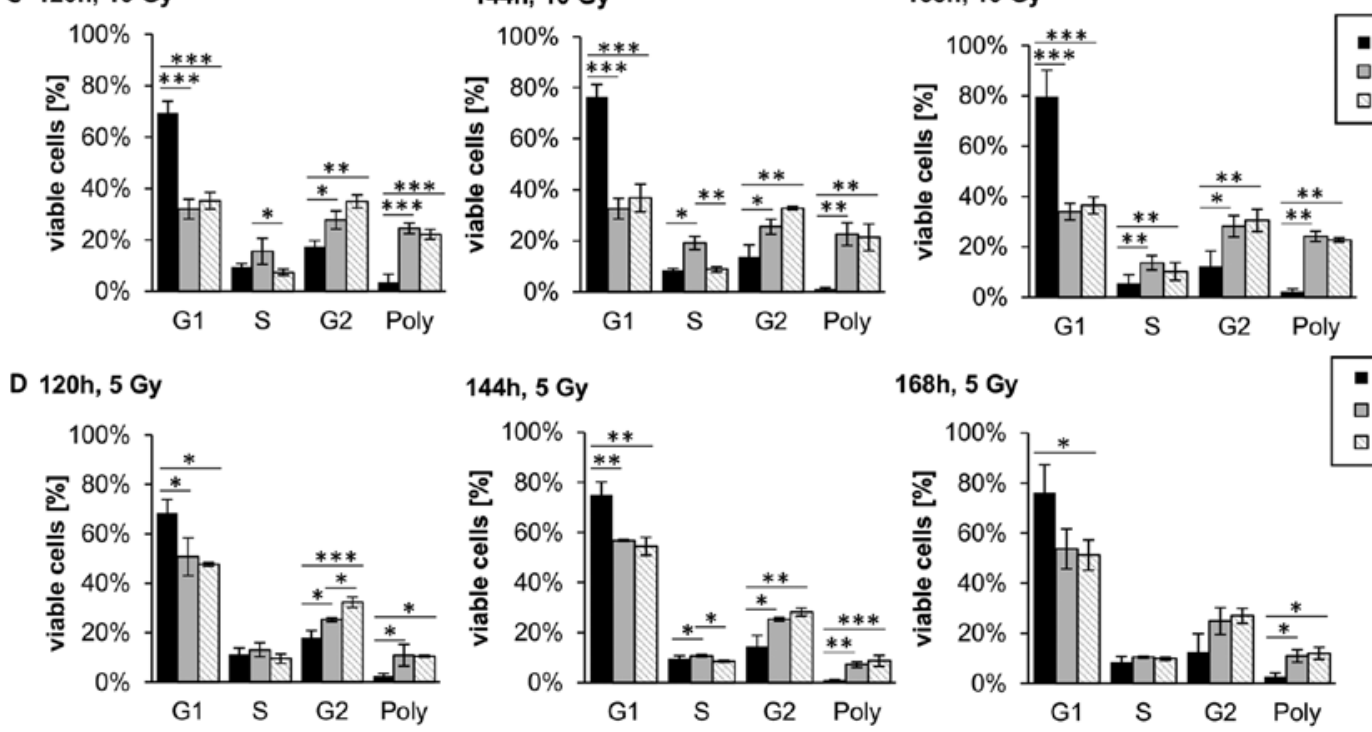

Figure 2. Different cellular responses observed between high single-dose irradiation (SD-IR) and fractionated dose irradiation (FD-IR) after 10 or 5 Gy irradiation in G35 differentiated cells. (A) Experimental chronology: G35 DCs were seeded $24 \mathrm{~h}$ before the first radiation (1.IR), and either re-irradiated or mock treated every $24 \mathrm{~h}$ for two additional cycles. (B) Induced DNA fragmentation as surrogate readout for apoptosis was assessed by flow cytometric analysis of propidium iodide-stained nuclei at indicated time-points (left panel), while viable cells were quantified using a CASY cytometer and are depicted as percentage of mock-treated cells (control) (right panel). (C) The cell cycle analysis was performed on viable cells at indicated time-points, the DNA content of which was visualized by propidium iodide-stained nuclei. Cells were either mock-treated (control), irradiated once with 10 Gy (SD-IR) or 5 times daily with 2 Gy (FD-IR). (D) The cell cycle analysis was performed on viable cells at indicated time-points, the DNA content of which was visualized by propidium iodide-stained nuclei. Cells were either mock-treated (control), irradiated once with $5 \mathrm{~Gy}$ (SD-IR) or 5 times daily with $1 \mathrm{~Gy}$ (FD-IR). Shown are the means \pm SD of three independent experiments performed in triplicate. In (B) statistical significance was always in relation to the untreated control group and assessed by an unpaired two-tailed $\mathrm{t}$-test; in (C and $\mathrm{D})$ statistical significance was assessed by a one-way ANOVA, followed by a Bonferroni post-hoc test $\left({ }^{*} \mathrm{P} \leq 0.05 ;{ }^{* *} \mathrm{P} \leq 0.01 ;{ }^{* * * *} \mathrm{P} \leq 0.001\right)$. 
A

\begin{tabular}{|ccccccccc} 
seeding & $1^{\text {st }} \mid R$ & $2^{\text {nd }} \mid R$ & $3^{\text {rd }} \mid R$ & $4^{\text {th }} \mid R$ & $5^{\text {th }} \mid R$ & $1^{\text {st }}$ measurement & $2^{\text {nd }}$ measurement & $3^{\text {rd }}$ measurement \\
\hline$-24 \mathrm{~h}$ & $\mid$ & $\mid$ & $\mid$ & $\mid$ & $\mid$ & $\mid$ & $\mid$ & $\mid$ \\
\hline
\end{tabular}

$\left.\begin{array}{lrlllll}1 \times 10 G y: & 10 G y & - & - & - & - & \\ 5 x & 2 G y: & 2 G y & 2 G y & 2 G y & 2 G y & 2 G y\end{array}\right\}$ total dose: $10 \mathrm{~Gy}$

B

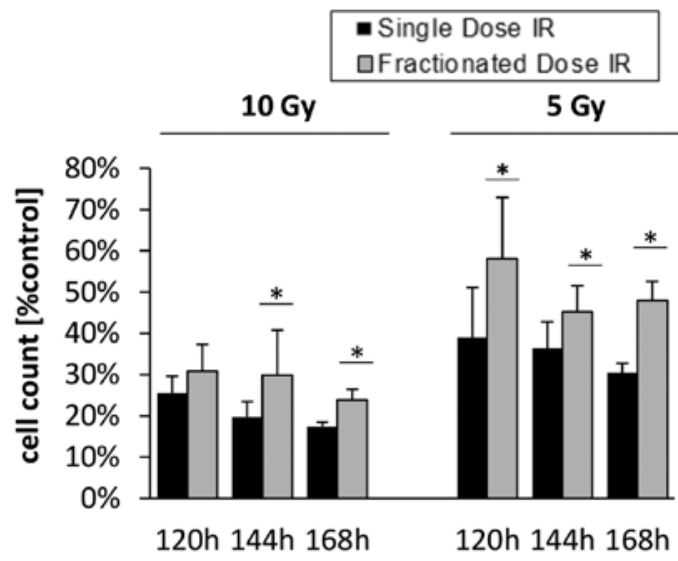

C
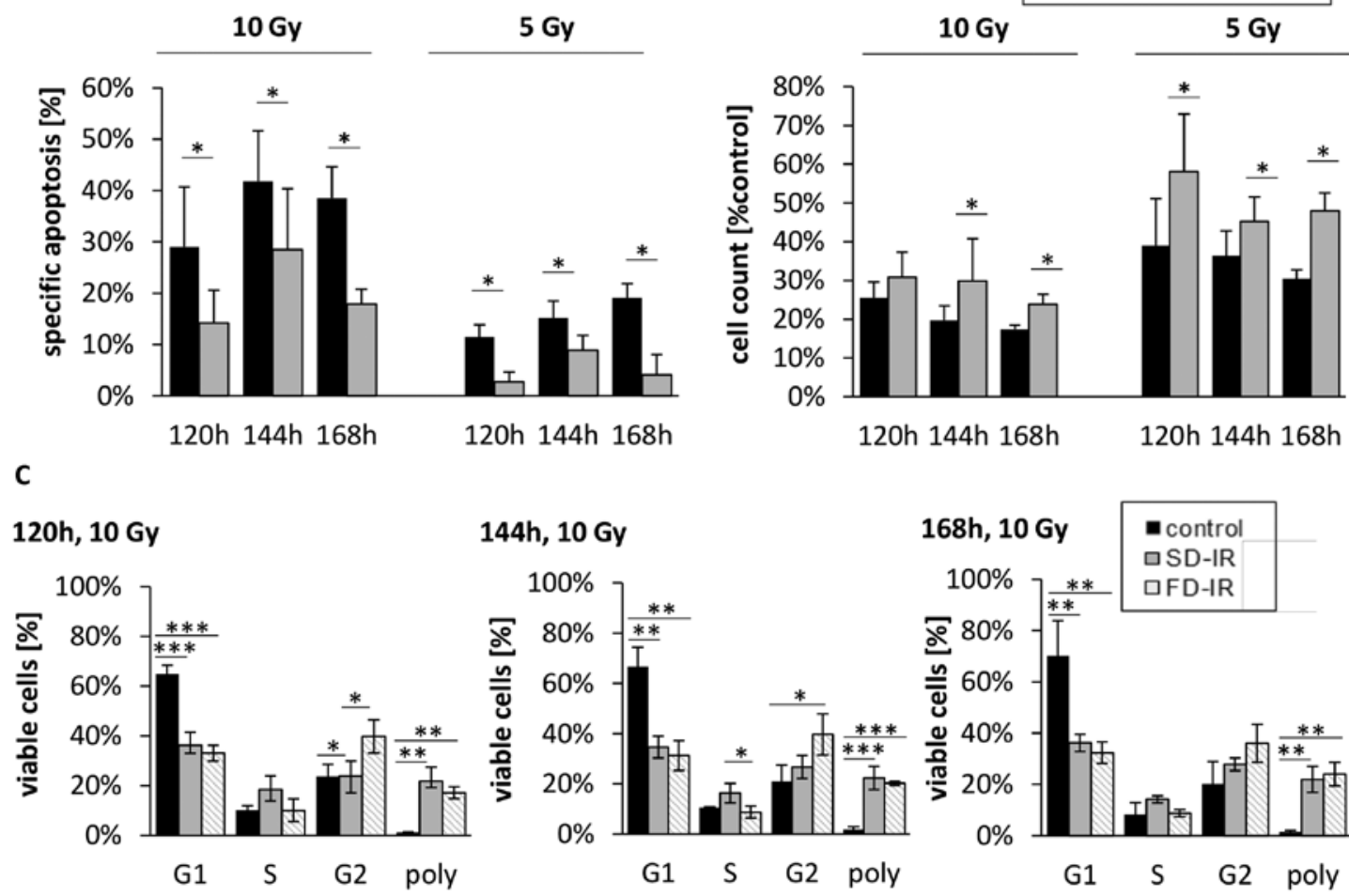

D
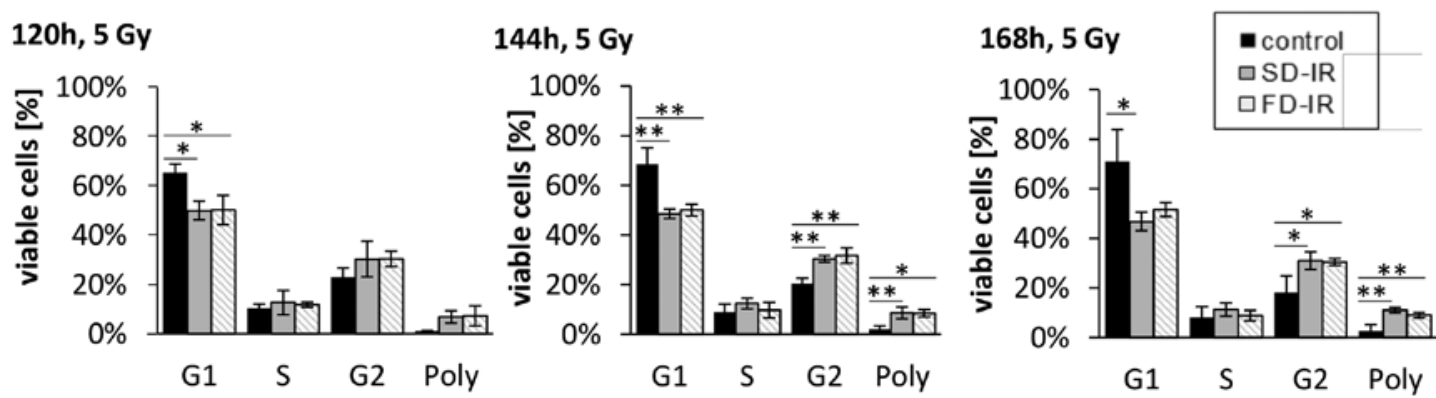

Figure 3. Different cellular responses observed between high single-dose irradiation (SD-IR) and fractionated dose irradiation (FD-IR) after 10 or 5 Gy irradiation in G38 differentiated cells. (A) Experimental chronology: G38 DCs were seeded 24 h before the first radiation (1.IR), and either re-irradiated or mock treated every $24 \mathrm{~h}$ for two additional cycles. (B) Induced DNA fragmentation as surrogate readout for apoptosis was assessed by flow cytometric analysis of propidium iodide-stained nuclei at indicated time-points (left panel), while viable cells were quantified using a CASY cytometer and are depicted as percentage of mock-treated cells (control) (right panel). (C) The cell cycle analysis was performed on viable cells at indicated times points, the DNA content of which was visualized by propidium iodide-stained nuclei. Cells were either mock-treated (control), irradiated once with 10 Gy (SD-IR) or 5 times daily with 2 Gy (FD-IR). (D) The cell cycle analysis was performed on viable cells at indicated time-points, the DNA content of which was visualized by propidium iodide-stained nuclei. Cells were either mock-treated (control), irradiated once with $5 \mathrm{~Gy}$ (SD-IR) or 5 times daily with $1 \mathrm{~Gy}$ (FD-IR). Shown are the means \pm SD of three independent experiments performed in triplicate. In (B) statistical significance was always in relation to the untreated control group and assessed by an unpaired two-tailed $\mathrm{t}$-test; in (C and D) statistical significance was assessed by a one-way ANOVA, followed by a Bonferroni post-hoc test $\left({ }^{*} \mathrm{P} \leq 0.05 ;{ }^{* *} \mathrm{P} \leq 0.01 ;{ }^{* * *} \mathrm{P} \leq 0.001\right)$.

current clinical schedule. In addition, we also looked at 5 Gy (either as single dose or fractionated into 5 doses of $1 \mathrm{~Gy}$ ); this reflects previous concerns of neurological decline which was not observed when fractions of 1 Gy were used (34). As shown in Fig. 2, FD-IR led to significantly lower rates of specific apoptosis (Fig. 2B) and significantly higher rates in cell count (Fig. 2C) than SD-IR. This, as well as the overexponential decrease in colony formation for doses $>6$ Gy (Fig. 1A) is likely due to the higher chance for multiple chromosomal breaks with higher incidence for mismatch repair (35). 
A

\begin{tabular}{|c|c|c|c|c|c|c|}
\hline $\begin{array}{c}\text { seeding } \\
1\end{array}$ & $\begin{array}{c}1^{\text {st }} \text { IR } \\
\mid\end{array}$ & $2_{1}^{2^{\text {nd }}} \mathrm{IR}$ & $\begin{array}{c}3^{\text {rd }} I R \\
\mid\end{array}$ & & & $\begin{array}{c}\text { measurement } \\
\mid\end{array}$ \\
\hline$-24 h$ & Oh & $24 \mathrm{~h}$ & $48 \mathrm{~h}$ & $72 \mathrm{~h}$ & $96 \mathrm{~h}$ & $120 \mathrm{~h}$ \\
\hline $\begin{array}{l}1 \text { x } 2 \text { Gy: } \\
2 \text { × } 2 \text { Gy: } \\
3 \text { × } 2 \text { Gy: } \\
1 \text { x } 6 \text { Gy: }\end{array}$ & $\begin{array}{l}2 \mathrm{~Gy} \\
2 \mathrm{~Gy} \\
2 \mathrm{~Gy} \\
6 \mathrm{~Gy}\end{array}$ & $\begin{array}{l}2 \overline{G y} \\
2 G y\end{array}$ & $2 \overline{G y}$ & & & \\
\hline
\end{tabular}

B

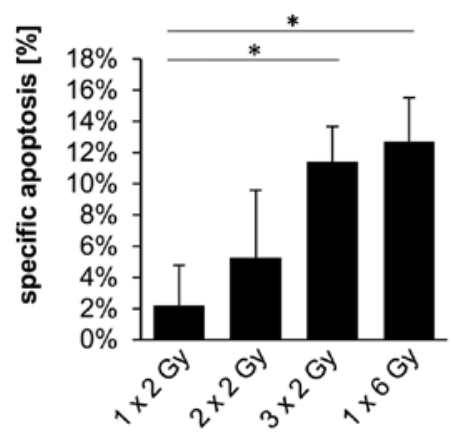

C

D

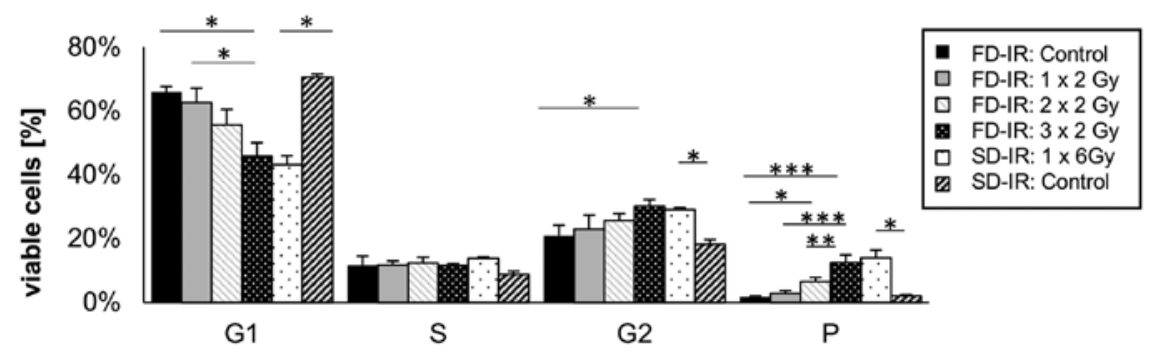

Figure 4. Different cellular responses observed between high single-dose irradiation (SD-IR) and fractionated dose irradiation (FD-IR) after 2 Gy, $2 \times 2$ Gy and $3 x G y$, but not between 3x2 Gy and 1x6 Gy. (A) Experimental chronology: G35 DCs were seeded $24 \mathrm{~h}$ before the first radiation (1.IR), and either re-irradiated or mock treated every $24 \mathrm{~h}$ for two additional cycles. (B) Induced DNA fragmentation as surrogate readout for apoptosis was assessed by flow cytometric analysis of Propidium Iodide-stained nuclei at indicated time-points (left panel), while viable cells were quantified using a CASY cytometer and are depicted as percentage of mock treated cells (control) (right panel). (C) The cell cycle analysis was performed on viable cells at indicated times points, the DNA content of which was visualized by propidium iodide-stained nuclei. Cells were either mock-treated once (control SD-IR) or trice (control FD-IR), or irradiated with indicated doses of $1 \times 2 \mathrm{~Gy}, 2 \times 2 \mathrm{~Gy}, 3 \times 2 \mathrm{~Gy}$ or $1 \times 6 \mathrm{~Gy}$. Shown are the means $\pm \mathrm{SD}$ of three independent experiments performed in triplicate; statistical significance was assessed by a one-way ANOVA, followed by a Bonferroni post-hoc test $\left({ }^{*} \mathrm{P} \leq 0.05 ;{ }^{* *} \mathrm{P} \leq 0.01 ;{ }^{* * *} \mathrm{P} \leq 0.001\right)$.

Of note, when examining the effect on cell cycle distribution, both FD-IR and SD-IR induced polyploidy to a similar extent; however, SD-IR seemed to lead to a greater accumulation of cells in the S phase, while cells treated with FD-IR appeared to favour the G2 phase (Fig. $2 \mathrm{C}$ and D). These patterns seem to be a general feature of irradiated, differentiated glioblastoma cells, as they were also observed in a secondary cell population (Fig. 3).

DNA damage responses following $3 \times 2$ Gy and 6 Gy irradiation. After having observed that a total of $10 \mathrm{~Gy}$ irradiation leads to a greater effect on cell death and changes in cell number (Figs. 2 and 3), we more closely investigated the effects of different rounds of radiation; i.e., we treated the cells with 1x2 Gy,2x2 Gy, 3x2 Gy and 1x6Gy radiation(Fig.4). Weobserved a dose-dependent effect on cell number and cell death, but no perceivable effect between $3 \times 2$ Gy and 1x6 Gy (Fig. 4B and C). Of note, only a dose of $6 \mathrm{~Gy}$ (single dose and fractionated) had a clear effect on the cell cycle distribution; a clear reduction of the percentage of cells in the G1 phase of cycle was observed, while a concurrent increase in the number of cells in the G2 phase and polyploidy were also observed (Fig. 4D). While no discernible differences between SD-IR and FD-IR were observed with regards to cell death induction, cell cycle distribution and total cell number, we, however, speculated that a difference between SD-IR and FD-IR could still be found in the activation of DNA-damage repair (DDR). In order to examine this hypothesis, we visualized foci formation of gamma/phospho-Histon H2AX. The phosphorylation of this histone at Ser139 occurs in response to DNA double-strand breaks and it has been proposed that this concentrates repair factors, such as RAD51, at sites of DNA damage (36). The cells were irradiated either with a 6 Gy single dose or with three fractions of 2 Gy every $24 \mathrm{~h}$ according to clinical standard schedule. In both groups, phospho-H2AX staining was monitored for three 24 -h cycles, which corresponded to $15 \mathrm{~min}, 4$ and $24 \mathrm{~h}$ after each fractionated dose of 2 Gy for the FD-IR group (Fig. 5A). Representative images of an individual cycle are shown in Fig. 5B, highlighting the fact that the phosphorylation of $\mathrm{H} 2 \mathrm{AX}$ is a rapid event, peaking within $15 \mathrm{~min}$ of damage induction/radiation and already considerably reduced after $4 \mathrm{~h}$. Within $24 \mathrm{~h}$, the amount and intensity of phospho-H2AX foci were almost back to background level. Repeated exposure to $2 \mathrm{~Gy}$ led to repeated rounds of $\mathrm{H} 2 \mathrm{AX}$ phosphorylation and, hence DNA repair (Fig. 5C). By contrast, a single exposure to 6 Gy led only to a single round of DNA repair, but surprisingly the cellular response, as assessed by the levels of phospho-H2AX foci, was similar to that for $1 \times 2$ and 1x6 Gy (Fig. 5C). 
A

\begin{tabular}{|c|c|c|c|c|c|}
\hline seeding & $1^{\text {st }}$ IR & & $2^{\text {nd }}$ IR & $3^{\text {rd } I R}$ & \\
\hline$-24 h$ & Oh & & $24 \mathrm{~h}$ & $48 \mathrm{~h}$ & $72 \mathrm{~h}$ \\
\hline & $\uparrow$ & $\uparrow$ & $\uparrow \uparrow \uparrow$ & $\uparrow \uparrow \uparrow$ & $\uparrow$ \\
\hline measurement: & $15 \mathrm{~min}$ & $4 \mathrm{~h}$ & $24 \mathrm{~h} 15 \min 4 \mathrm{~h}$ & $24 \mathrm{~h} 15 \mathrm{~min} 4 \mathrm{~h}$ & $24 \mathrm{~h}$ \\
\hline
\end{tabular}

B
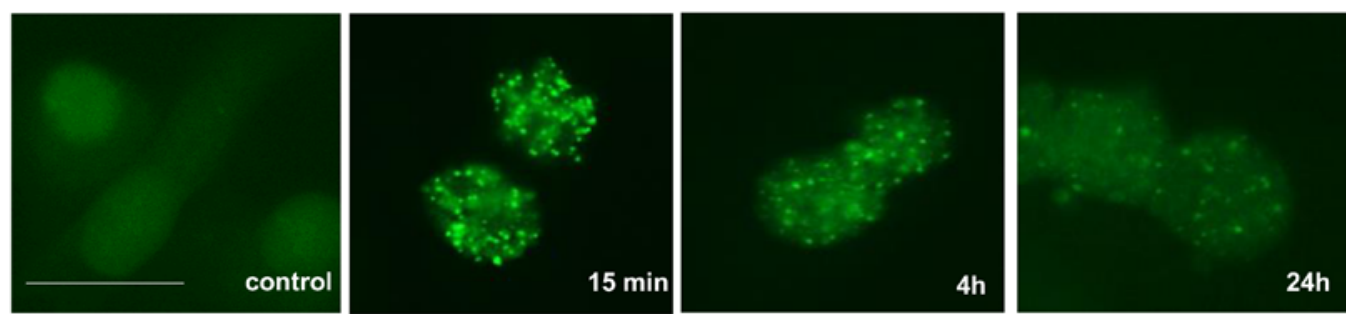

C

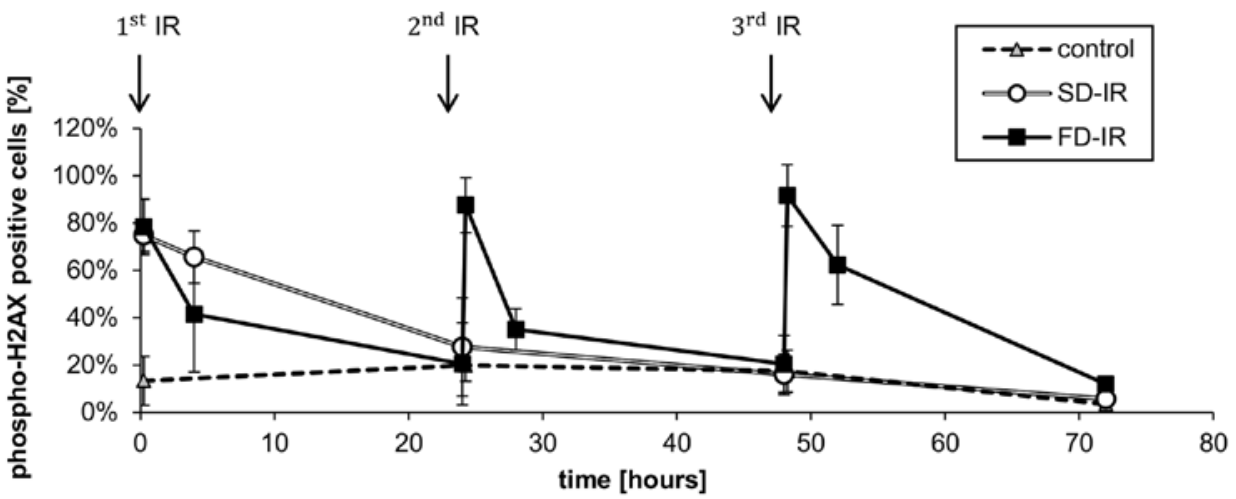

Figure 5. Different DNA damage response after high single-dose irradiation (SD-IR) and fractionated dose irradiation (FD-IR). (A) Experimental chronology: G35 DCs were seeded $24 \mathrm{~h}$ before the first radiation and re-irradiated every $24 \mathrm{~h}$ in the FD-IR group, or mock treated in the SD-IR group. Irradiation was delivered either once (SD-IR 1x6 Gy) or in fractions (FD-IR 3x2 Gy). (B) Cells were fixed in formaldehyde and immunohistochemically stained with phospho$\mathrm{H} 2 \mathrm{AX}$, as surrogate marker for a DNA damage response. and examined with a fluorescence microscope. Representative images of phospho-H2AX stained cells $15 \mathrm{~min}, 4$ and $24 \mathrm{~h}$ after 2 Gy single dose irradiation are shown. Scale bar, $25 \mu \mathrm{m}$. (C) The percentage of phospho-H2AX-positive cells was determined after counting cells $15 \mathrm{~min}, 4$ and $24 \mathrm{~h}$ after (mock) irradiation. Cells with $>10$ foci per nucleus were considered positive. Shown is the means \pm SD of three independent experiments.

A role of PI3K signalling in irradiated glioblastoma cells. Subsequently, we investigated whether PI3K plays a role in the cellular response of a glioblastoma DC population to irradiation. As we have previously shown that PI3K signalling, via DNA-PK, contributes to DNA repair and that the sequential association between apoptosis inducer (herein, radiation) and sensitizer (herein, pharmacological inhibition of PI3K signalling) play a critical role in designing a successful combination therapy [(37,38), respectively], we devised, after confirming the inhibition of PI3K signalling via GDC-0941 (Fig. 6A), a complex schedule to maximize potential combinations (Fig. 6B). The addition of $625 \mathrm{nM}$ GDC-0941, a concentration we have previously shown to induce the rapid and prolonged inhibition of PI3K signalling in glioblastoma DCs (20), had a synergistic effect on cell numbers when combined with $3 \times 2$ Gy irradiation (Fig. 6C). This effect, independent of the schedule selected, was not mediated via increased cell death (Fig. 6C and D, respectively). Furthermore, the total effect on cell numbers that the combined use of irradiation with PI3K inhibition has, also appears rather minor or, at least, temporally limited, as a long-term colony forming assay indicated that the clear effect that $3 \times 2$ Gy had on colony numbers was not enhanced by the addition of GDC-0941 (Fig. 6E).

As this synergetic effect on cell numbers was clearly not due to increased apoptosis, we speculated whether this may be due to the combined effects of PI3K inhibition and radiation on the cell cycle. The inhibition of PI3K has been found to exert a cytostatic effect on glioblastoma cells (17) and under the experimental conditions applied herein, a transient arrest at the G1 phase of the cell cycle was also observed (Fig. 7A). Of note, the combination of GDC-0941 and radiation led to an increase in the number of cells in the $\mathrm{G} 2$ phase, as did, although to a lesser extent, radiation on its own (Fig. 7B). Whether these effects on cell cycle progression combine and lead to a reduction in cell numbers, or whether PI3K inhibition prolongs the radiation-mediated cell cycle arrest via a mechanism that is independent of its direct effect on cell cycle progression needs to be further elucidated in the future. Alternatively, it is conceivable that DNA repair, which can also be dependent on PI3K signalling (17), is retarded by GDC-0941-mediated inhibition, i.e., the cells take longer to repair radiation-induced damages when PI3K signalling is impaired.

There are several lines of evidence suggesting that radiotherapy can increase tumour cell mobility $(11,39,40)$. As our own data strongly suggest that the PI3K pathway mediates cell motility in glioblastoma cell lines, as well as DCs $(19,20)$, we determined via a scratch assay that this is also true in our experimental system (Fig. 8A and B). This is in line with our previous data which showed that GDC-0941 inhibited the motility of G40 and G35 DCs (20). 
A

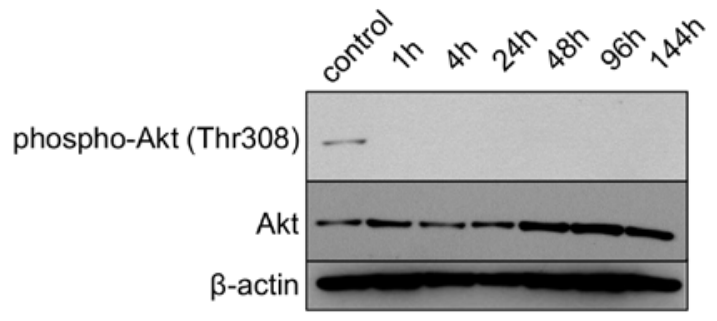

B

\begin{tabular}{|c|c|c|c|c|c|c|c|c|c|}
\hline & $-24 h$ & $\mathrm{Oh}$ & $24 \mathrm{~h}$ & $48 \mathrm{~h}$ & $72 \mathrm{~h}$ & $96 \mathrm{~h}$ & $120 \mathrm{~h}$ & $144 \mathrm{~h}$ & $168 \mathrm{~h}$ \\
\hline group & I & I & I & I & । & । & | & I & I \\
\hline $1 \mathrm{~h}<1^{s t}$ & seeding & GDC>2 Gy & 2 Gy & 2 Gy & - & - & - & measurement & - \\
\hline $1 \mathrm{~h}>1^{s t}$ & seeding & $2 \mathrm{~Gy}>\mathrm{GDC}$ & $2 \mathrm{~Gy}$ & $2 \mathrm{~Gy}$ & - & - & - & measurement & - \\
\hline $1 \mathrm{~h}>3^{\text {rd }}$ & seeding & $2 \mathrm{~Gy}$ & $2 \mathrm{~Gy}$ & $2 \mathrm{~Gy}>\mathrm{GDC}$ & - & - & - & measurement & - \\
\hline $24 \mathrm{~h}<1^{s t}$ & seeding & GDC & $2 \mathrm{~Gy}$ & 2 Gy & $2 \mathrm{~Gy}$ & - & - & - meas & uremen \\
\hline
\end{tabular}

C

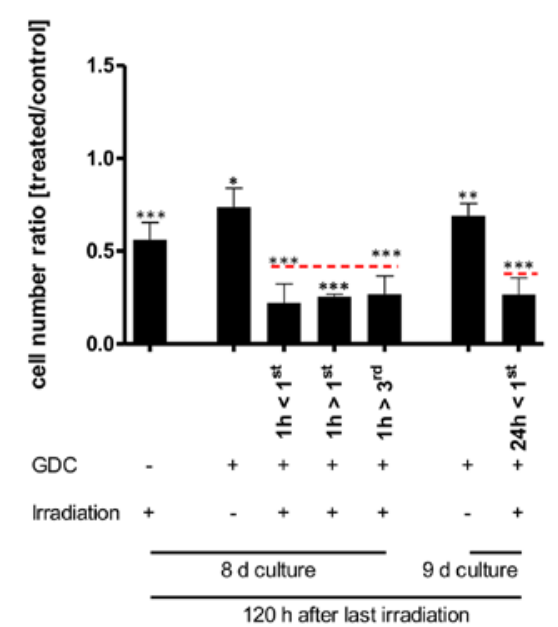

D

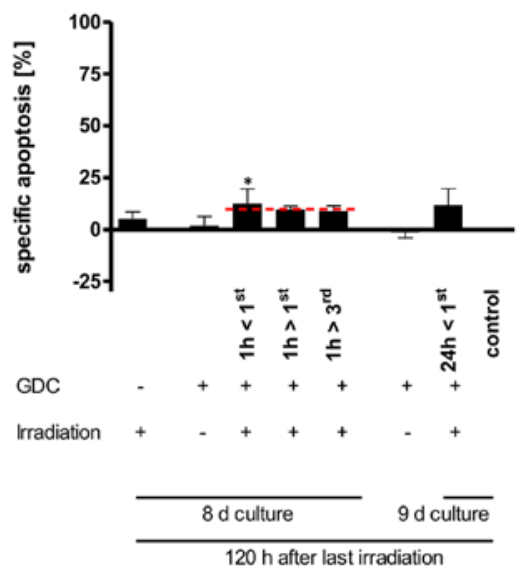

E
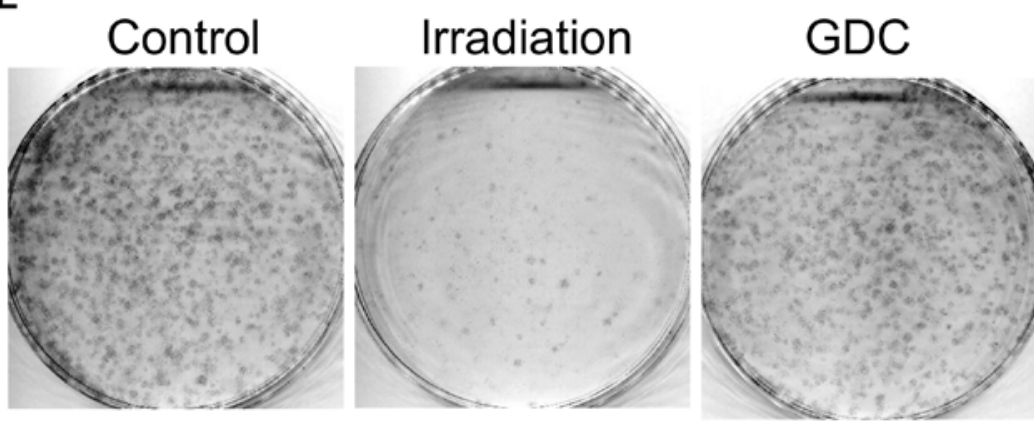

Combination

Figure 6. Effects of combining GDC-0941 and fractionated dose irradiation (FD-IR) on apoptosis and cell numbers. (A) Addition of $625 \mathrm{nM}$ GDC-0941 (GDC) leads to a rapid and prolonged inhibition of PI3K-mediated signalling, as assessed by using the phosphorylation of Akt as a surrogate readout. Protein expression and phosphorylation was assessed for untreated cells or cells treated for indicated times by western blot analysis. (B) Experimental chronology: G40 DCs were seeded $24 \mathrm{~h}$ before the first intervention and treated as indicated. 2 Gy, irradiation with 2 Gy; GDC, stimulation with $0.625 \mu \mathrm{M}$ GDC-0941. If both treatments were applied on the same day, the first named was given $1 \mathrm{~h}$ prior $(>)$ to the latter, $144 \mathrm{~h}$ after the first irradiation dose cells were analysed. (C) Viable cells were quantified using a CASY cytometer and are depicted as percentage of mock treated cells (control). (D) Induced DNA fragmentation as surrogate readout for apoptosis was assessed by flow cytometric analysis of propidium iodide-stained nuclei at indicated time-points. Red lines indicate an additive effect. In (C and D) statistical significance was assessed by a one-way ANOVA, followed by a Bonferroni post-hoc test $\left({ }^{*} \mathrm{P} \leq 0.05\right.$; $\left.{ }^{* *} \mathrm{P} \leq 0.01 ;{ }^{* * *} \mathrm{P} \leq 0.001\right)$. (E) Cells were treated with GDC-0941 $1 \mathrm{~h}$ after the first irradiation round. After the final irradiation, adherent cells were re-seeded at a low density. After 11 days cells were fixed and stained. In ( $A$ and $E$ ) one representative result of two independent experiments is depicted. In $(C$ and $D)$ the means $\pm S D$ of at least three independent experiments performed in triplicate are shown.

We then looked at the speed of motility in untreated cells, irradiated cells and irradiated cells treated with GDC-0941 (Fig. 8C). Irradiation caused an increase in motility, which was still clearly detectable $32 \mathrm{~h}$ after radiation exposure ( $0-8 \mathrm{~h}$ of measurement). This effect was blocked by post-radiation exposure of the cells to GDC-0941, at later time-points (8-24 h); the inhibition of PI3K reduced motility even below the levels found in untreated cells. In the context of tumour growth, increased motility can also contribute to increased invasion; therefore, we performed an invasion assay 

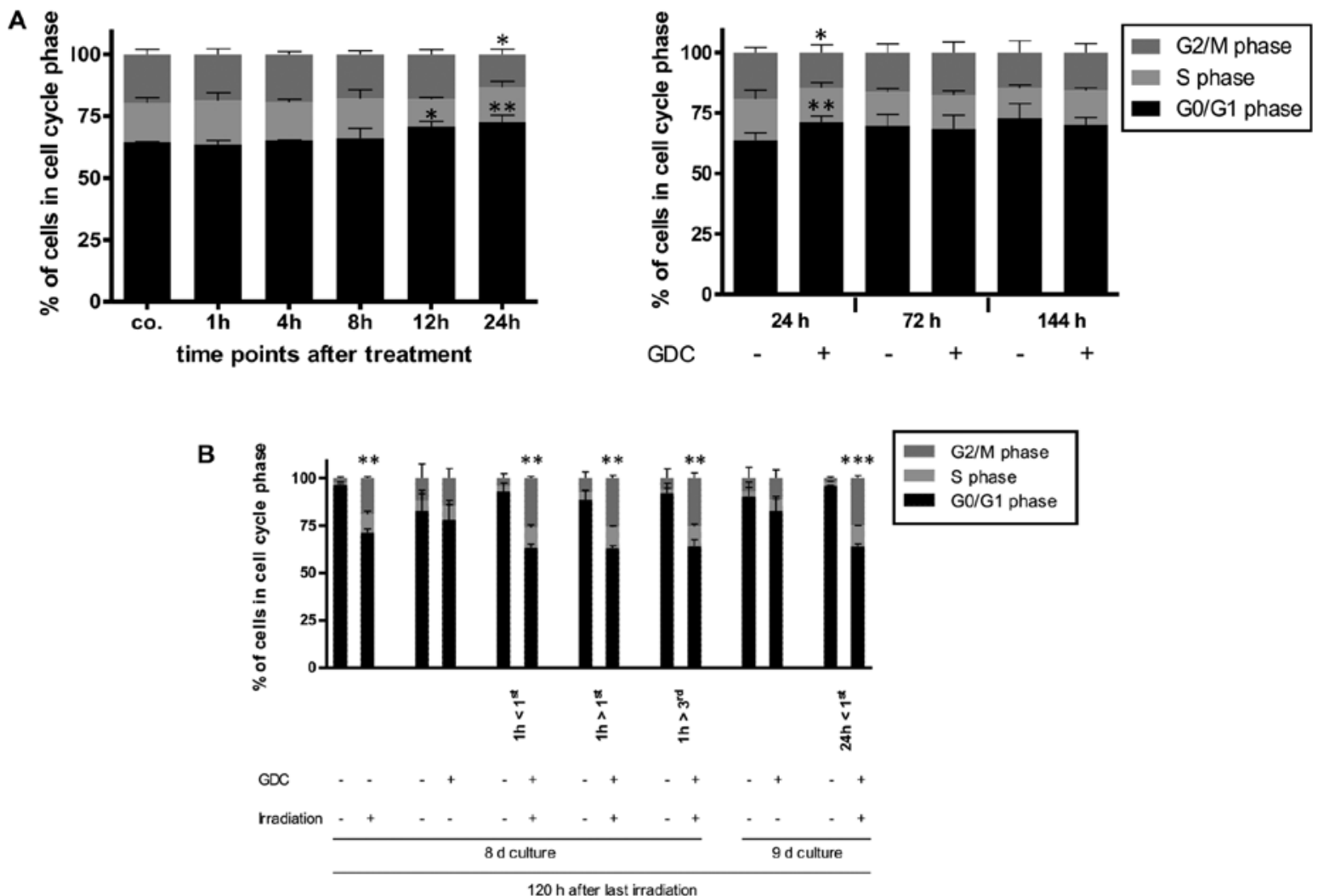

Figure 7. Possible molecular basis for the effects of combining GDC-0941 and fractionated dose irradiation (FD-IR). (A) Flow cytometric analysis of propidium iodide-stained nuclei was performed to detect cells in different phases of cell cycle. Left panel, GDC-0941 treatment of G40 DCs was performed 24, 12 , 8, 4 and $1 \mathrm{~h}$ prior to control (co.). Right panel, 24, 72 and $144 \mathrm{~h}$ after GDC-0941 treatment, the analysis was performed with paired controls. (B) The effect of the different treatment combination on the cell cycle distribution of viable cells is depicted by cytometric analysis of propidium iodide-stained nuclei. Depicted are means \pm SD of three independent experiments performed in triplicate. In (A) statistical significance was assessed by a one-way ANOVA, followed by a Bonferroni post-hoc test; in (B) statistical significance was always in relation to the untreated control group and assessed by unpaired two-tailed t-test ( $\mathrm{P} \leq 0.05$; $\left.{ }^{* *} \mathrm{P} \leq 0.01 ;{ }^{* * *} \mathrm{P} \leq 0.001\right)$.

to examine the effects of radiation on glioblastoma cell invasion and whether PI3K inhibition can potentially reduce cell invasion. As suggested by the data shown in Fig. 9A, and as it is a general feature of glioblastoma cells, three independent populations were investigated, and the results revealed that the combination of radiation and GDC-0941 led to a reduced cellular invasion through a collagen-coated matrix. For the G40 DCs, this effect was highly significant and led to a reduction of approximately $25 \%$ less invasive cells compared to the control alone (Fig. 9B). Therefore, the inhibition of PI3K not only blocks the radiation-induced increase in motility, but when GDC-0941 was used in combination with radiation, this generally led to a reduction in invasion.

Finally, we investigated the effects of GDC-0941 and radiation on SCs. Similar to its effect in DCs, GDC-0941 led to a prolonged inhibition of PI3K-mediated signalling, as assessed by the phosphorylation of Akt, a key mediator of PI3K-mediated signalling (Fig. 10A). However, in the SCs, the inhibition of PI3K did not lead to a reduction in motility or a cell cycle arrest (Fig. 10B and C, respectively), supporting our previous observations that the PI3K signalling cascade has distinct functions within different populations of an individual tumour (20). With the combination of GDC-0941 and radiation, a mostly synergistic reduction in total the cell number was detected (Fig. 11A); however, in contrast to our findings in DCs, a synergistic effect on apoptosis induction was also detectable (Fig. 11B). We previously described a similar pattern when treating SCs and DCs with temozolomide (20). The surviving SC population displayed a similar increase in the number of cells in the $\mathrm{G} 2$ phase as observed in the DCs (Figs. 7B and 11C, respectively), as in the SCs, GDC-0941 alone did not lead to an increase in the G1 population (Fig. 11C) nor to a reduction in cell numbers over time (20), it appears that the increase in the G2 cell number upon combination therapy is not due to the synergetic effects of cell cycle inhibition, but rather to the reduced repair capacities of the cell populations.

Another difference between the SCs and DCs became apparent when analysing cellular motility, as neither radiation nor radiation and the PI3K inhibitor in combination affect the locomotive capacity of SCs (Fig. 11D).

In summary, while the inhibition of PI3K signalling did not sensitize the glioblastoma DC population to radiationinduced apoptosis, it did contribute to a synergistic effect on cell numbers, e.g., by blocking proliferation, and reduced the intrinsic speed of surviving irradiated cells, thereby reducing their invasive potential. This is in contrast to the SC population, which was sensitised to radiation-induced cell death, but whose motility remained unaffected by radiation or PI3K inhibition. This suggests an important role for PI3K inhibition in future combination therapies designed for the treatment of glioblastoma. 
A
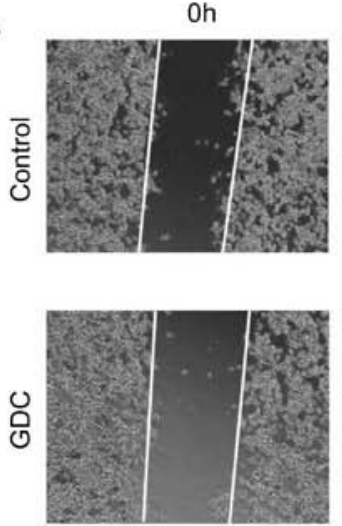

Oh

\section{B}
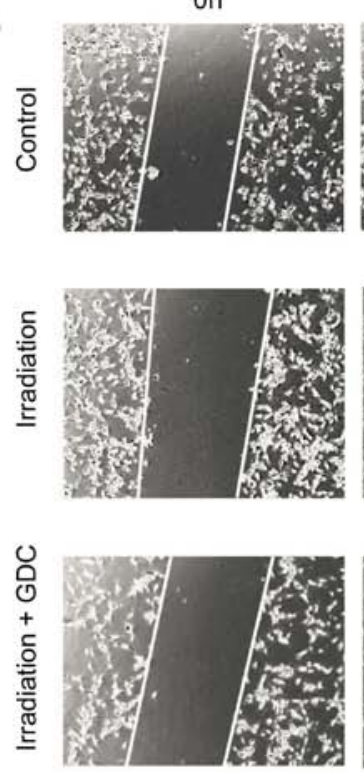

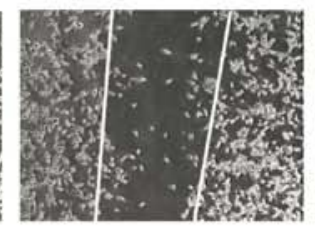

$8 \mathrm{~h}$
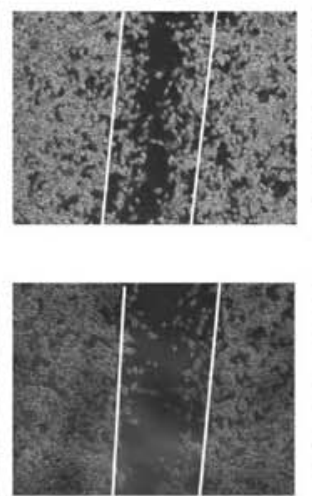

8h

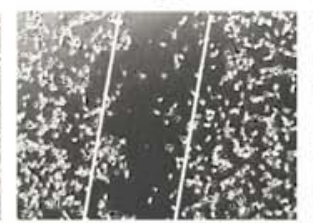

$16 \mathrm{~h}$
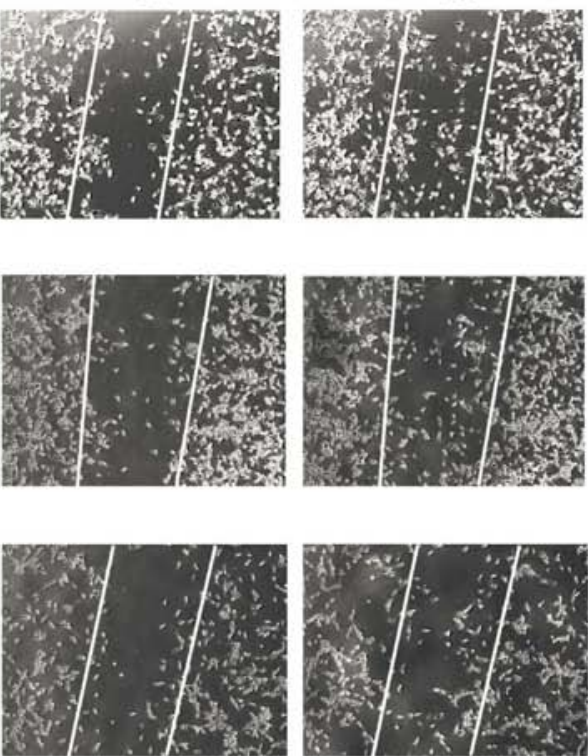

$16 \mathrm{~h}$
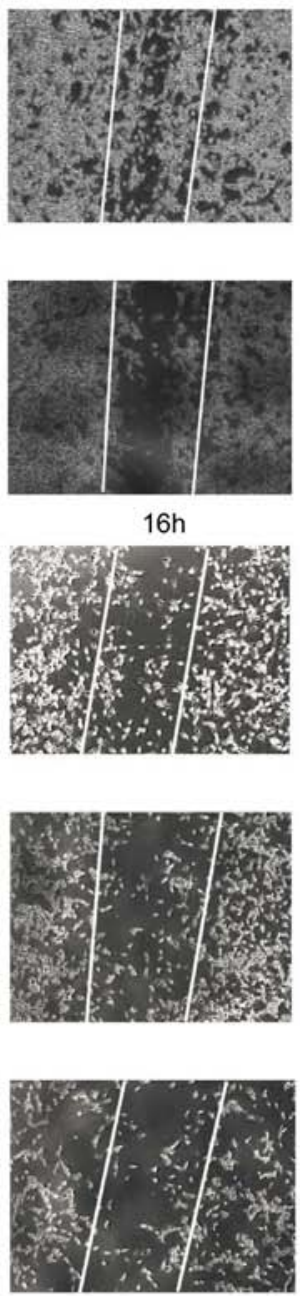
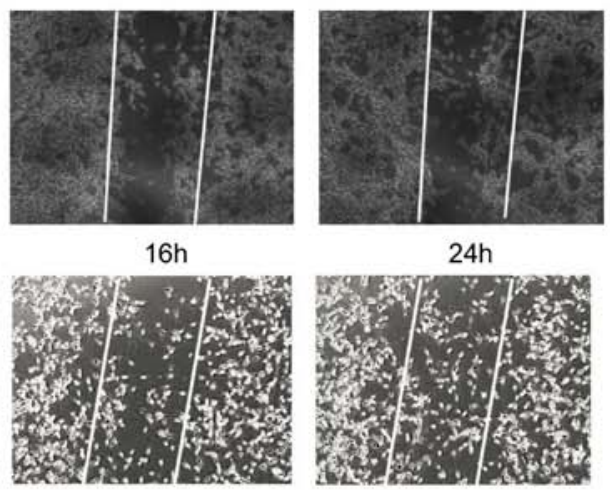

24h

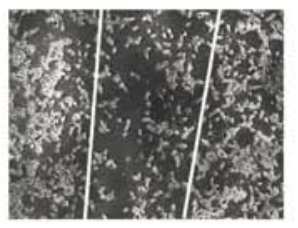

$24 \mathrm{~h}$
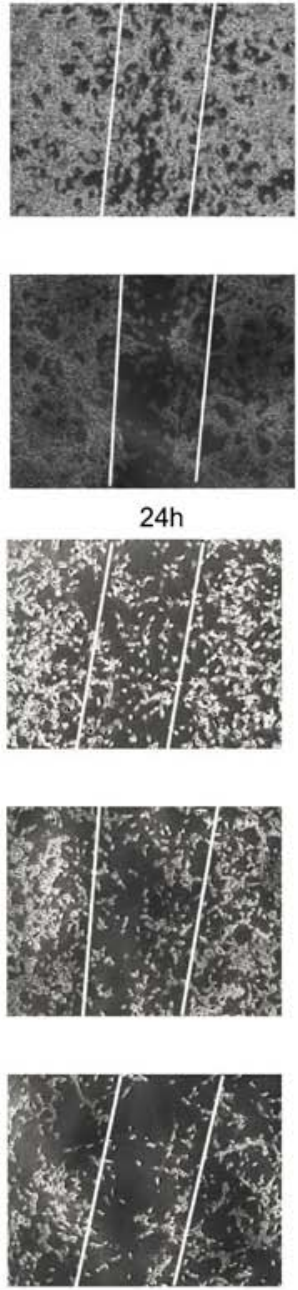

C

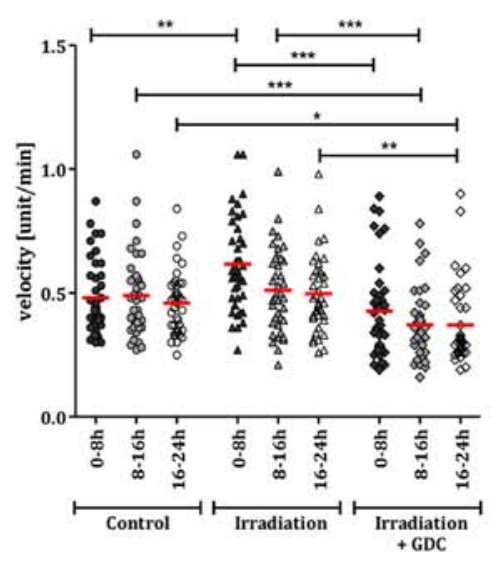

Figure 8. Effects of the combined use of GDC-0941 and fractionated dose irradiation (FD-IR) on motility. (A) After culturing G40 differentiated cells (DCs) overnight, cells were either left untreated or treated for 30 min with $0.625 \mu \mathrm{M}$ GDC-0941 (GDC). This was followed by the introduction of a single wound, represented by the white lines. Twenty-four hours time-lapse microscopy was initiated 30min after wounding. (B) Cells were irradiated with three times 2 Gy (Irradiation) or not (Control) and, after culturing G40 DCs overnight, were either treated for 30 min with $0.625 \mu \mathrm{M}$ GDC-0941 (Irradiation + GDC) or not. This was followed by the introduction of a single wound, represented by the white lines. At $24 \mathrm{~h}$ time-lapse microscopy was initiated 30 min after wounding. In (A and B) one representative result of two independent experiments performed in duplicate is depicted. (C) Irradiated (3x2 Gy) and non-irradiated cells were allowed to grow for $24 \mathrm{~h}$ after seeding and were treated with GDC-0941 $1 \mathrm{~h}$ before recording via time-lapse microscopy for another $24 \mathrm{~h}$. Cell velocity was examined in 8-h intervals using ImageJ software. The mean of two experiments performed in duplicate is shown ( $\mathrm{n}=40$ ). Statistical significance was assessed by two-way ANOVA ( $\left.\mathrm{P} \leq 0.05 ;{ }^{* *} \mathrm{P} \leq 0.01 ;{ }^{* * *} \mathrm{P} \leq 0.001\right)$.

\section{Discussion}

Glioblastoma, the most common primary brain tumour, is also considered one of the most lethal cancers per se, contributing to $2 \%$ of the worldwide tumour burden and $7 \%$ of years lost due to cancer before the age of $70(3,41,42)$. This is highly unusual for a tumour that only rarely metastasizes outside the neuroaxis, as only 0.4 to $2.0 \%$ of all glioblastoma patients 
A
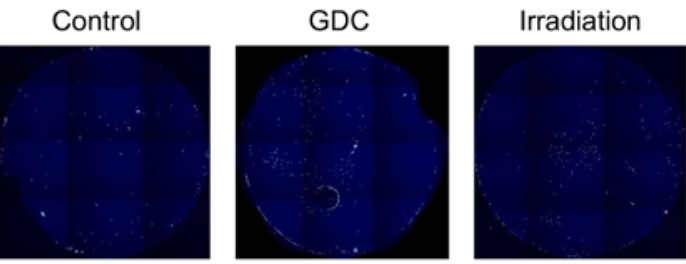

Irradiation + GDC

G35
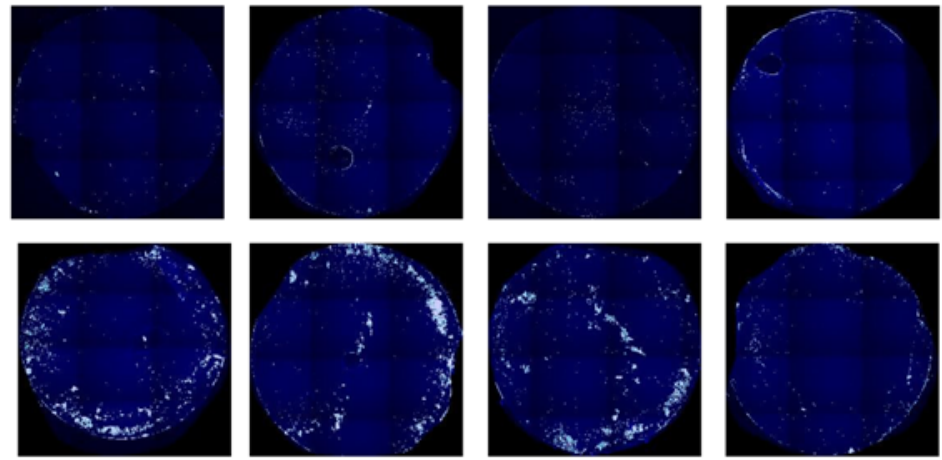

$\mathrm{G} 38$
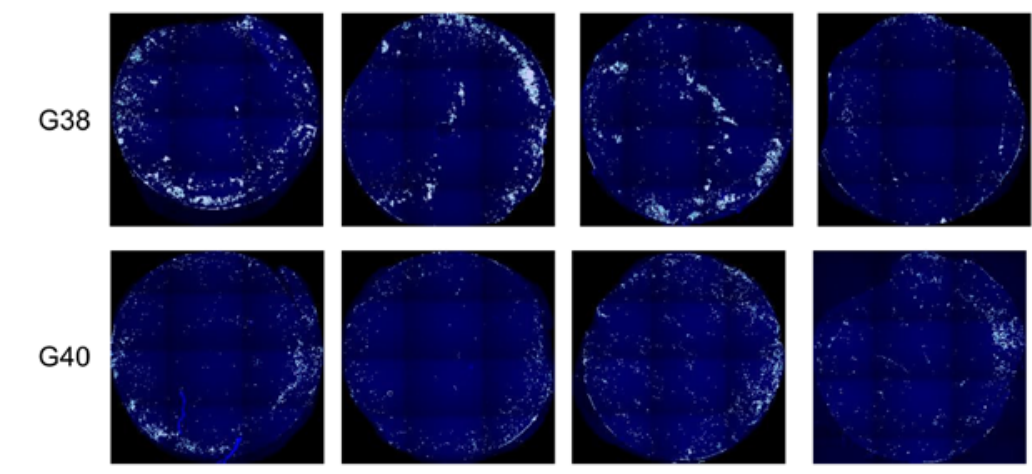

B
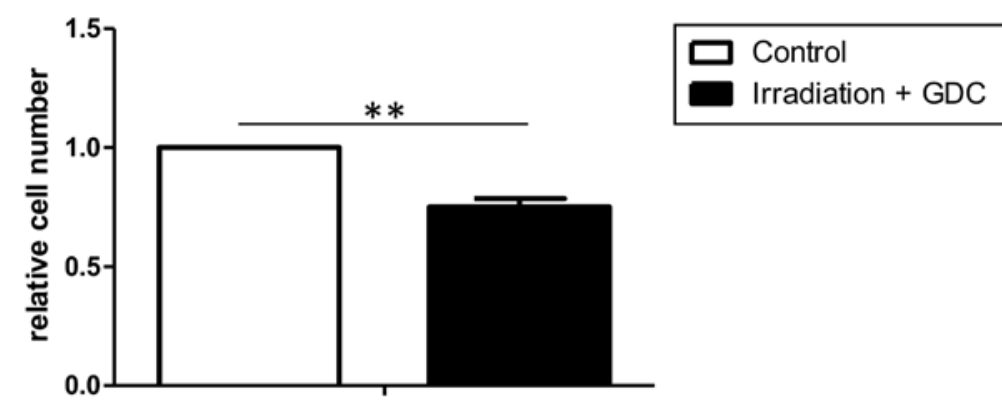

Transmiarated cells

Figure 9. Effects of the combined use of GDC-0941 and fractionated dose irradiation (FD-IR) on invasion. (A) Following exposure to either 0 (Control, GDC) or 2 Gy (Irradiation, Irradiation + GDC), cells were left untreated overnight. This was followed by seeding cells in serum-free medium in the presence (GDC, Irradiation + GDC) or absence (Control, Irradiation) of $0.625 \mu \mathrm{M}$ GDC-0941 on collagen-coated membranes. After allowing migration towards serumcontaining medium for $24 \mathrm{~h}$, cells were fixed and stained. (B) Statistical evaluation of the experiment shown in (A) for G40 differentiated cells (DCs). Shown in (A) are exemplary images of at least two independent experiments, and in (B) the means \pm SD of three independent experiments are depicted. Statistical significance was assessed by an unpaired two-tailed t-test $\left.{ }^{* * *} \mathrm{P} \leq 0.01\right)$.

exhibit extracranial/extra-CNS metastases $(3,43,44)$. However, glioblastoma does not produce a clearly delineated encapsulated tumour within in the brain, but is characterized by a diffuse, infiltrative growth pattern (45), and it has even been suggested that glioblastoma has more in common with a systemic, i.e., whole brain disorder than with a typical spreading tumour within the brain $(46,47)$. This limits the possible therapeutic approaches significantly.

Full safe surgical resection of glioblastoma is impossible due to the infiltrative nature of the disease; following the removal of the tumour bulk (which can significantly alleviate symptoms), recurrence occurs in $95 \%$ of cases $2-3 \mathrm{~cm}$ from the initial tumour location (2). By contrast, chemotherapeutic intervention is often limited by the ability of the drug to cross the blood-brain-barrier (BBB). Currently, the only chemotherapeutic agent that is part of the standard treatment is temozolomide, which efficiently crosses the BBB, but only prolongs average patient survival by approximately two months (6). While the BBB can be compromised within the tumour bulk (48), drug delivery to the individual invading cells is still reduced. Indeed, it has been postulated that the inhibitor used in this study, GDC-0941, only accumulates at high concentrations in the tumour bulk, and that it is less well distributed throughout the healthy brain, i.e., does not reach invading cells at sufficiently high concentrations (49).

From the 1960s, it was suggested to utilize radiotherapy for malignant brain tumours $[(50,51)$ for example] and a decade later, it was established that $50 \mathrm{~Gy}$ was too ineffective (52), while 70 to 80 Gy were too necrotizing (53). By 1990, the current suggestion of 60 Gy in 2 Gy daily fraction was established (54). However, it is common practise for in vitro investigations of glioblastoma to use a high individual radiation dose (such as $6 \mathrm{~Gy}$ ) to mimic repeated treatment with the clinically applied dose of 2 Gy [for example (55-62)]. While this may be logistically easier and expose cell cultures to less stress, our data clearly indicate that a high SD-IR is a poor surrogate for FD-IR. Clear differences in the apoptotic rate, cell number and cell cycle distribution could be observed, particularly when comparing 10 Gy with $5 \times 2$ Gy. Furthermore, even at doses where no apparent differences in apoptosis induction, cell numbers and cell cycle distribution could be discerned, e.g., when comparing SD-IR of 6 Gy with FD-IR of $3 \times 2$ Gy, the cellular response was clearly different to a single or fractionated dose. Of note, the initial doses of 
A

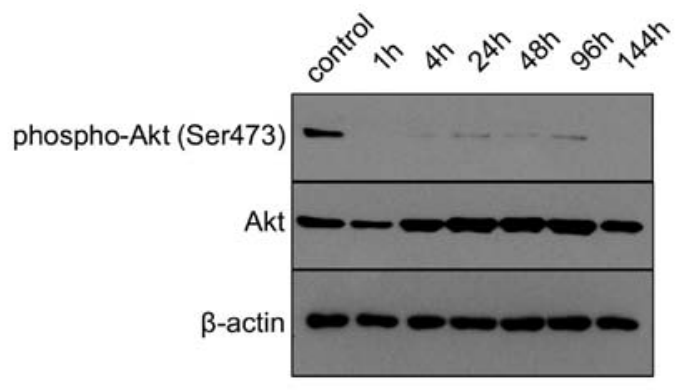

B

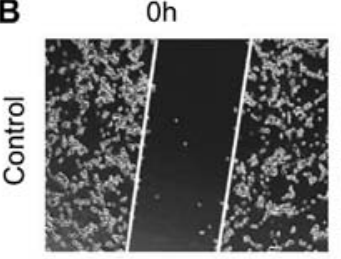

O

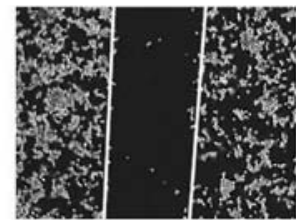

$8 \mathrm{~h}$

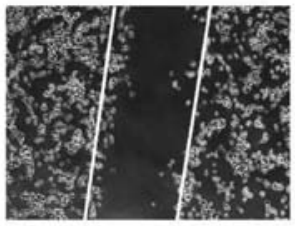

$16 \mathrm{~h}$
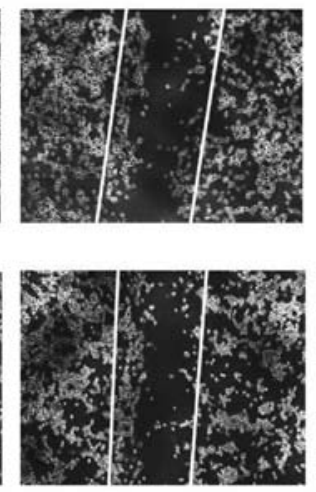

$24 \mathrm{~h}$
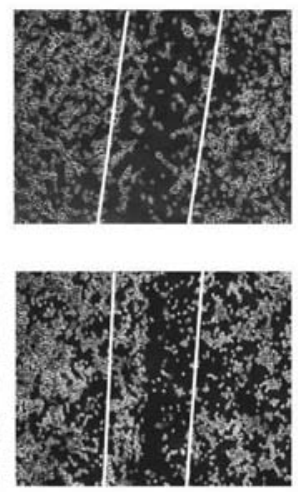
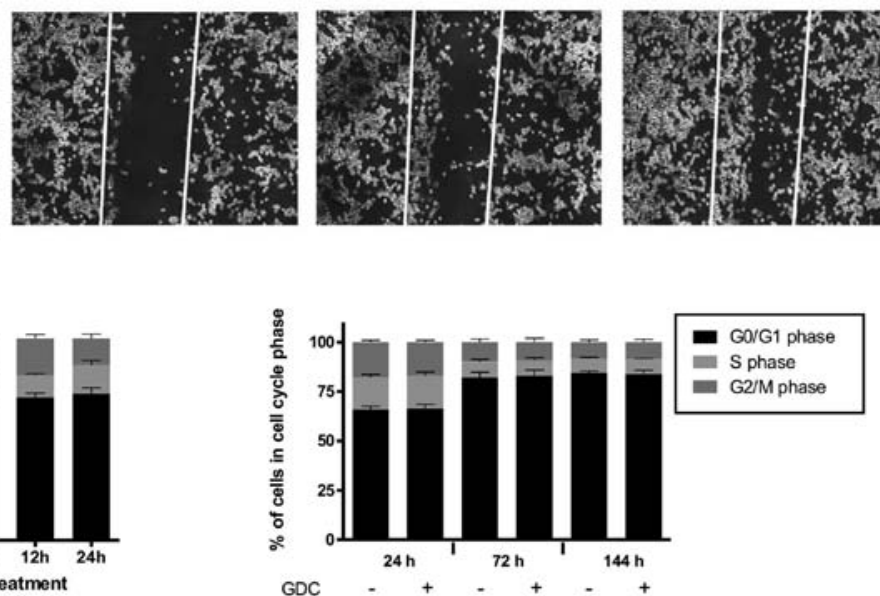

Figure 10. Effects of GDC-0941 on glioblastoma stem cell-like cells (SCs). (A) Addition of 625 nM GDC-0941(GDC) led to a rapid and prolonged inhibition of PI3K-mediated signalling, as assessed by using phosphorylation of Akt as a surrogate readout. Protein expression and phosphorylation was assessed for untreated cells or cells treated for indicated times by western blot analysis. (B) After culturing G40 SCs on collagen-coated plastic overnight, cells were either left untreated or treated for $30 \mathrm{~min}$ with $0.625 \mu \mathrm{M}$ GDC-0941 (GDC). This was followed by the introduction of a single wound, represented by the white lines. At $24 \mathrm{~h}$ time-lapse microscopy was initiated $30 \mathrm{~min}$ after wounding. (C) Flow cytometric analysis of propidium iodide-stained nuclei was performed to detect cells in different phases of cell cycle. Left panel, GDC-0941 treatment of G40 SCs was performed 24, 12, 8, 4 and 1 h prior to control (co.). Right panel, 24, 72 and $144 \mathrm{~h}$ after GDC-0941 treatment the analysis was performed with paired controls. In (A) one representative result of two independent experiments is depicted; in (B) one representative result of two independent experiments performed in triplicate is depicted; and in (C) the means \pm SD of at least three independent experiments performed in triplicate are shown.

2 and 6 Gy caused a DNA repair response in a similar fraction of cells (approximately 80\%). This DNA repair response, however, does not reflect the reaction of the cell populations to different doses of radiation, as 6 Gy induced significantly more apoptosis, more strongly reduced total cell numbers and differentially altered the cell cycle than $2 \mathrm{~Gy}$. It is possible that the lower dose led to a more rapid repair, as suggested by the increased reduction of phospho-H2AX-positive cells in the FD-IR group after $1 \mathrm{~h}$, although the differences between SD-IR and FD-IR were not significant. Prior to the second cycle, the percentage of phospho-H2AX-positive cells was similar in the 2 and 6 Gy-treated populations and indistinguishable from the control population. Repeated exposure to radiation led to a similarly strong DNA damage response, but after the third round of irradiation, phospho-H2AX foci were clearly retained longer. As this occurs within $52 \mathrm{~h}$ of the first exposure to $2 \mathrm{~Gy}$, it is not a genetic selection of a subpopulation that leads to this difference. Whether this prolonged foci retention reflects a more robust DNA damage response, or results from an energic depletion of the DNA repair machinery after multiple rounds of repair, remains unclear. It does, however, highlight a clear difference between SD-IR and FD-IR and the inaptitude of using SD-IR to mimic the effects of FD-IR.

While there can be little doubt about the importance of radiation as part of the standard cancer therapy, there are still unwanted consequences of applying it, such as increase motility in the surviving fraction of tumour cells (63). For example, following $10 \mathrm{~Gy}$ irradiation, surviving lung cancer cells exhibit both an increased motility and invasiveness (39), via molecular pathways we have also observed to be increased in stressed glioblastoma cells (21). In addition, it has also been reported that a post-radiational increase in VEGF increases the motility of glioblastoma cells (11), while radiation has also been linked to increased motility by inducing epithelial-mesenchymal transition in lung epithelial cells (40). We observed a similar event in this study when analysing the locomotive capacity and 
A

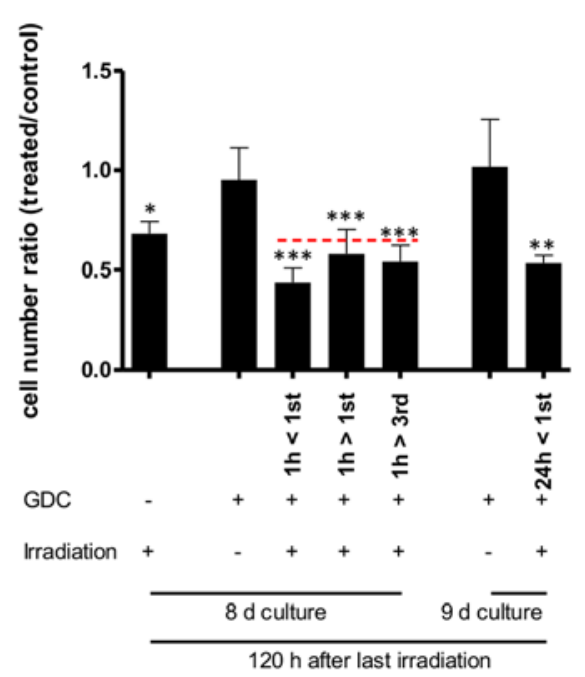

B

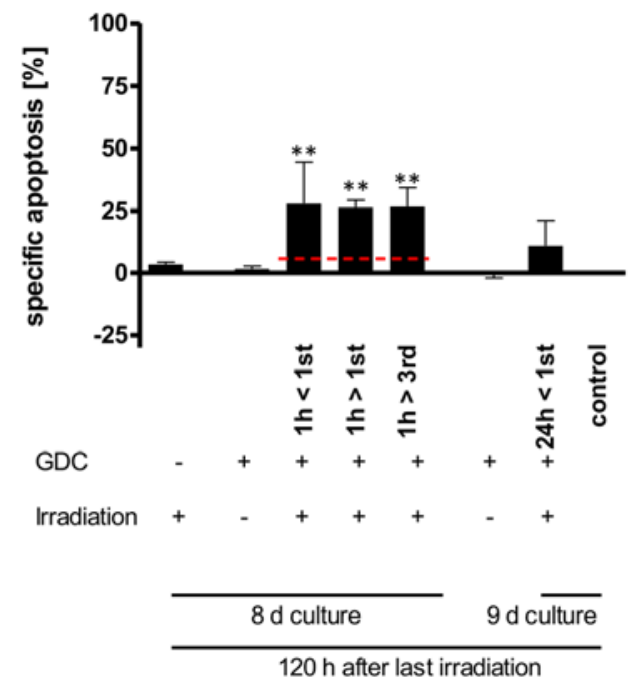

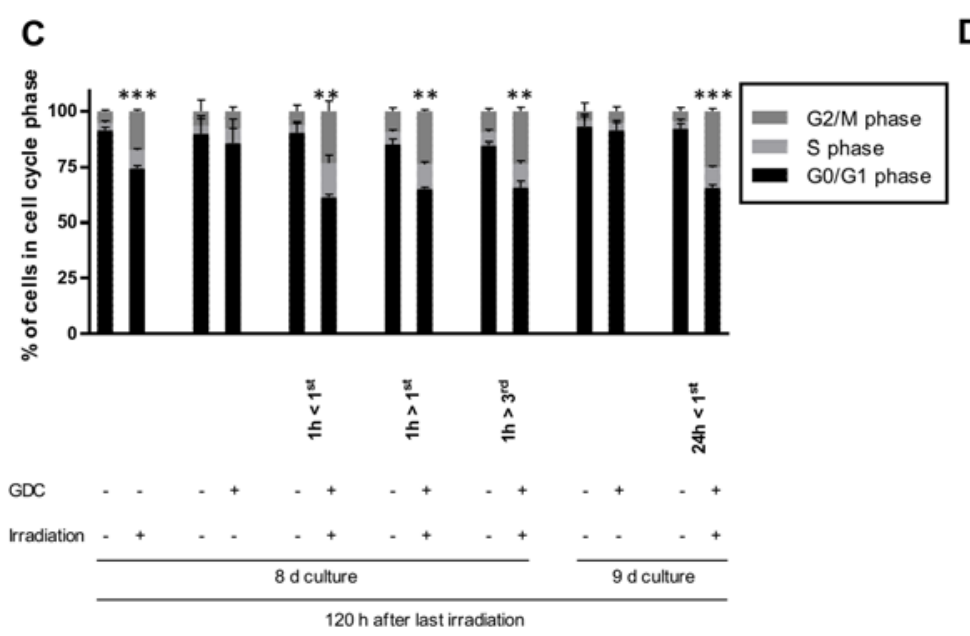

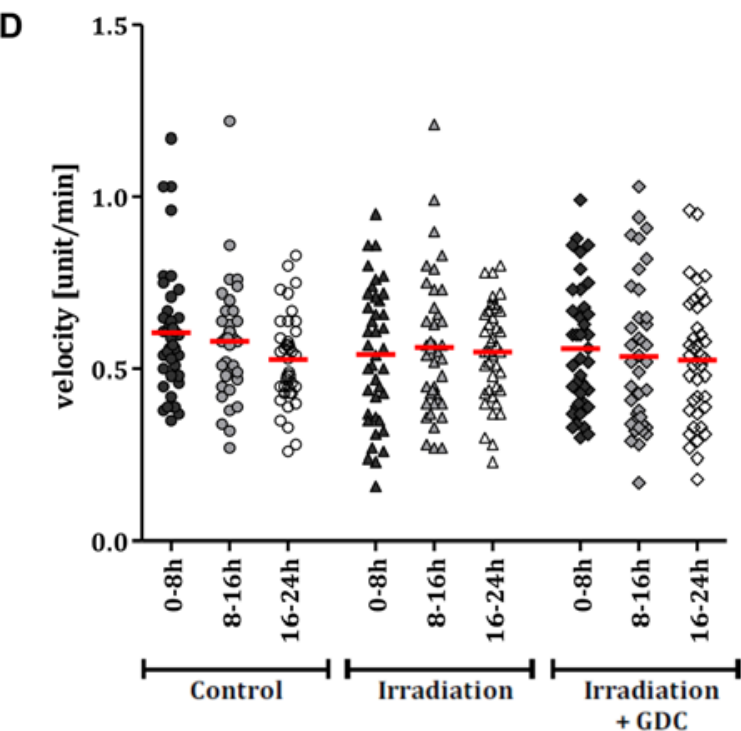

Figure 11. Effects of combining GDC-0941 and FD-IR on glioblastoma stem cell-like cells (SCs). (A) G40 SCs were treated similar to the experimental chronology outlined in Fig. 5B. Viable cells were quantified using a CASY cytometer and are depicted as percentage of mock-treated cells (control). (B) Induced DNA fragmentation as surrogate readout for apoptosis was assessed by flow cytometric analysis of propidium iodide-stained nuclei at indicated time-points. Red lines indicate an additive effect. (C) The effect of the different treatment combination on the cell cycle distribution of viable cells is depicted by cytometric analysis of propidium iodide-stained nuclei. In (A-C) the means \pm SD of at least three independent experiments performed in triplicate are shown. In (A and B) statistical significance was assessed by a one-way ANOVA, followed by a Bonferroni post-hoc test; and in (C) statistical significance was always in relation to the untreated control group and assessed by an unpaired two-tailed t-test $\left({ }^{*} \mathrm{P} \leq 0.05 ;{ }^{* *} \mathrm{P} \leq 0.01 ;{ }^{* * * *} \mathrm{P} \leq 0.001\right)$. (D) Irradiated $(3 \times 2 \mathrm{~Gy})$ and non-irradiated cells were allowed to grow for $24 \mathrm{~h}$ after seeding and were treated with GDC-0941 $1 \mathrm{~h}$ before recording via time-lapse microscopy for a further $24 \mathrm{~h}$. Cell velocity was examined in 8-h intervals using ImageJ software. Mean of two experiments performed in duplicate is shown $(\mathrm{n}=40)$. Statistical significance was assessed by two-way ANOVA.

invasive potential of irradiated DCs and showed that increased motility could be prevented by combining radiation treatment with GDC-0941, a pharmacological inhibitor of PI3K signalling, the most commonly activated survival cascade in glioblastoma $(14,15)$. In addition, the inhibition of PI3K did not sensitize the DC population to radiation-induced cell death, but synergized with radiotherapy to reduce cell numbers. Importantly, the single addition of GDC-0941 was not sufficient to maintain this effect on the long-term, as observed in the colony forming assays. Therefore, when considering the therapeutic implementation of PI3K inhibition in a clinical context, it will not be sufficient to reduce PI3K-mediated signalling only during irradiation, but persistently. Our own recent study demonstrated that a single signalling cascade, such as the PI3K pathway, can have distinct functions within a single tumour, depending on the population investigated (20). While blocking PI3K signalling alleviates the additional chemoresistance of the SC population to temozolomide, i.e., SCs became as sensitive/resistant to the drug as DCs were, no further sensitisation of the DC population was observed (20). By contrast, blocking PI3K significantly impeded the motility of DCs, but had no effect on SCs (20). In this study, we expanded on these findings, showing that these findings are also true for radiotherapy, but importantly we verified that DCs that survived radiation were more motile than untreated cells and that the addition of GDC-0941 reduced motility below that of untreated cells. This is in contrast to the SC population, where no effect on motility was observed, neither an increase after irradiation, nor a decrease after GDC-0941 treatment. The motility of cells is a prerequisite for invasion, 
and reducing it will hopefully block the spread of glioblastoma cells throughout the brain and create are more localised disease. This, naturally, can cause also a better response to chemotherapy, as more malignant cells will be reached by drugs locally penetrating through the leaking BBB associated with the tumour bulk. A similar approach has recently been described for breast cancer, where chemotherapy was found to facilitate increased metastasis, which, in turn, could be blocked by the addition of the pharmacological inhibitor rebastinib (64). Importantly, the reduction of motility does not lead to an increase in proliferation, the so-called 'the cost of migration' or 'go or grow' dilemma $(65,66)$, as the inhibition of PI3K signalling is both anti-proliferative and anti-migratory in a glioblastoma subpopulation (20).

In conclusion, this work demonstrates that using high SD-IR to mimic repeated cycles of FD-IR only provides a poor surrogate for the cellular response, both in terms of cell death and effects on the cell cycle. Importantly, repeated irradiation with low doses of radiation rapidly alters the cellular DNA damage repair response, an effect which cannot occur with SD-IR. In addition, we demonstrate that already the DC population of glioblastoma, which comprises the largest fraction within the tumour, is highly resistant to radiation (comparable to established cell lines). Modulation of the PI3K does not sensitize these cells for apoptosis; however, combining radiotherapy with pharmacological inhibitors of this signalling cascade appears to be beneficial with regards to reduction in cell numbers and blocking the increased invasive potential of surviving irradiated tumour cells. By contrast, the SC population can be sensitized for radiation by blocking PI3K signalling, but neither radiation nor GDC-0941 affect their migratory capacity. Therefore, combining PI3K inhibitors with radiotherapy appears to be a promising therapeutic avenue which warrants further investigation.

\section{Acknowledgements}

The authors would like to thank Mrs. C. Payer and Mrs. A. Schuster of the Department of Pediatrics and Adolescent Medicine, University Medical Center Ulm for their expert technical assistance.

\section{Funding}

MAW and KMD were partially supported by the Förderkreis für tumor- und leukämiekranke Kinder Ulm e.V., GKM by a Dr Mildred Scheel postdoctoral scholarship of the German Cancer Aid, and SH and SS were supported by The Experimental Medicine Program of the International Graduate School in Molecular Medicine Ulm of Ulm University.

\section{Availability of data and materials}

The datasets used and/or analysed during the current study are available from the corresponding author on reasonable request.

\section{Authors' contributions}

SH, LS, SS, JL, MS and SZ performed most of the experiments and analysed the data. GKM, SZ, GKM, MG, LN, MDS and
MEH provided support and materials, helped conceive key aspects of the study and analysed the data. KMD and MAW conceived and designed the study and wrote the manuscript. All authors have read and approved the final manuscript.

\section{Ethics approval and consent to participate}

The tumour specimens obtained for the culturing glioblastoma stem cell-like cells was approved by the Ethics Committee, Medical Faculty, Ulm University and after obtaining written consent from the patients. All methods were performed in accordance with the relevant guidelines and regulations.

\section{Patient consent for publication}

Not applicable.

\section{Competing interests}

The authors declare that they have no competing interests.

\section{References}

1. Vargo MM. Brain tumors and metastases. Phys Med Rehabil Clin N Am 28: 115-141, 2017.

2. Giese A, Bjerkvig R, Berens ME and Westphal M: Cost of migration: Invasion of malignant gliomas and implications for treatment. J Clin Oncol 21: 1624-1636, 2003.

3. Hamilton JD, Rapp M, Schneiderhan T, Sabel M, Hayman A, Scherer A, Kröpil P, Budach W, Gerber P, Kretschmar U, et al: Glioblastoma multiforme metastasis outside the CNS: Three case reports and possible mechanisms of escape. J Clin Oncol 32: e80-e84, 2014.

4. Burger PC, Heinz ER, Shibata T and Kleihues P: Topographic anatomy and CT correlations in the untreated glioblastoma multiforme. J Neurosurg 68: 698-704, 1988.

5. Berens ME and Giese A: '...those left behind.' Biology and oncology of invasive glioma cells. Neoplasia 1: 208-219, 1999.

6. Stupp R, Mason WP, van den Bent MJ, Weller M, Fisher B, Taphoorn MJ, Belanger K, Brandes AA, Marosi C, Bogdahn U, et al; European Organisation for Research and Treatment of Cancer Brain Tumor and Radiotherapy Groups; National Cancer Institute of Canada Clinical Trials Group: Radiotherapy plus concomitant and adjuvant temozolomide for glioblastoma. N Engl J Med 352: 987-996, 2005.

7. Johnson DR and O'Neill BP: Glioblastoma survival in the United States before and during the temozolomide era. J Neurooncol 107: 359-364, 2012.

8. Cuddapah VA, Robel S, Watkins S and Sontheimer H: A neurocentric perspective on glioma invasion. Nat Rev Neurosci 15: 455-465, 2014

9. Shibamoto Y, Miyakawa A, Otsuka S and Iwata H: Radiobiology of hypofractionated stereotactic radiotherapy: What are the optimal fractionation schedules? J Radiat Res (Tokyo) 57 (Suppl 1): i76-i82, 2016.

10. Wild-Bode C, Weller M, Rimner A, Dichgans J and Wick W: Sublethal irradiation promotes migration and invasiveness of glioma cells: Implications for radiotherapy of human glioblastoma. Cancer Res 61: 2744-2750, 2001.

11. Kil WJ, Tofilon PJ and Camphausen K: Post-radiation increase in VEGF enhances glioma cell motility in vitro. Radiat Oncol 7: 25, 2012.

12. Floyd NS, Woo SY, Teh BS, Prado C, Mai WY, Trask T, Gildenberg PL, Holoye P, Augspurger ME, Carpenter LS, et al: Hypofractionated intensity-modulated radiotherapy for primary glioblastoma multiforme. Int J Radiat Oncol Biol Phys 58: 721-726, 2004.

13. Hingorani M,Colley WP,DixitS and Beavis AM: Hypofractionated radiotherapy for glioblastoma: Strategy for poor-risk patients or hope for the future? Br J Radiol 85: e770-e781, 2012.

14. Cancer Genome Atlas Research Network: Comprehensive genomic characterization defines human glioblastoma genes and core pathways. Nature 455: 1061-1068, 2008. 
15. Fan QW and Weiss WA: Targeting the RTK-PI3K-mTOR axis in malignant glioma: Overcoming resistance. Curr Top Microbiol Immunol 347: 279-296, 2010.

16. Georgakis GV, Li Y, Rassidakis GZ, Medeiros LJ, Mills GB, Younes A: Inhibition of the phosphatidylinositol-3 kinase/Akt promotes G1 cell cycle arrest and apoptosis in Hodgkin lymphoma. Br J Haematol 132: 503-511, 2006.

17. Westhoff MA, Karpel-Massler G, Brühl O, Enzenmüller S, La Ferla-Brühl K, Siegelin MD, Nonnenmacher L and Debatin KM: A critical evaluation of PI3K inhibition in glioblastoma and neuroblastoma therapy. Mol Cell Ther 2: 32, 2004

18. Wen PY, Lee EQ, Reardon DA, Ligon KL and Alfred Yung WK: Current clinical development of PI3K pathway inhibitors in glioblastoma. Neuro Oncol 14: 819-829, 2002.

19. Ströbele S, Schneider M, Schneele L, Siegelin MD, Nonnenmacher L, Zhou S, Karpel-Massler G, Westhoff MA, Halatsch ME and Debatin KM: A potential role for the inhibition of PI3K signaling in glioblastoma therapy. PLoS One 10: e0131670, 2015.

20. Langhans J, Schneele L, Trenkler N, von Bandemer H, Nonnenmacher L, Karpel-Massler G, Siegelin MD, Zhou S, Halatsch ME, Debatin KM, et al: The effects of PI3K-mediated signalling on glioblastoma cell behaviour. Oncogenesis 6: 398 , 2017.

21. Westhoff MA, Zhou S, Nonnenmacher L, Karpel-Massler G, Jennewein C, Schneider M, Halatsch ME, Carragher NO, Baumann B, Krause A, et al: Inhibition of NF-kappaB signaling ablates the invasive phenotype of glioblastoma. Mol Cancer Res 11: 1611-1623, 2013

22. Westhoff MA, Zhou S, Bachem MG, Debatin KM and Fulda S Identification of a novel switch in the dominant forms of cell adhesion-mediated drug resistance in glioblastoma cells. Oncogene 27: 5169-5181, 2008.

23. Fowler JF: The linear-quadratic formula and progress in fractionated radiotherapy. Br J Radiol 62: 679-694, 1989.

24. Giagkousiklidis S, Vogler M, Westhoff MA, Kasperczyk H, Debatin KM and Fulda S: Sensitization for gamma-irradiationinduced apoptosis by second mitochondria-derived activator of caspase. Cancer Res 65: 10502-10513, 2005.

25. Facchino S, Abdouh M and Bernier G: Brain cancer stem cells: current status on glioblastoma multiforme. Cancers (Basel) 3: 1777-1797, 2011.

26. Schneider M, Ströbele S, Nonnenmacher L, Siegelin MD, Tepper M, Stroh S, Hasslacher S, Enzenmüller S, Strauss G, Baumann B, et al A paired comparison between glioblastoma 'stem cells' and differentiated cells. Int J Cancer 138: 1709-1718, 2016

27. Beier D, Schulz JB and Beier CP: Chemoresistance of glioblastoma cancer stem cells - much more complex than expected. Mol Cancer 10: 128, 2011.

28. Alphonse G, Maalouf M, Battiston-Montagne P, Ardail D, Beuve M, Rousson R, Taucher-Scholz G, Fournier C and Rodriguez-Lafrasse C: p53-independent early and late apoptosis is mediated by ceramide after exposure of tumor cells to photon or carbon ion irradiation. BMC Cancer 13: 151, 2013.

29. Cordes N, Hansmeier B, Beinke C, Meineke V and van Beuningen D: Irradiation differentially affects substratumdependent survival, adhesion, and invasion of glioblastoma cell lines. Br J Cancer 89: 2122-2132, 2003.

30. Short SC, Martindale C, Bourne S, Brand G, Woodcock M and Johnston P: DNA repair after irradiation in glioma cells and normal human astrocytes. Neuro Oncol 9: 404-411, 2007.

31. Hall JS, Iype R, Senra J, Taylor J, Armenoult L, Oguejiofor K, $\mathrm{Li}$ Y, Stratford I, Stern PL, O'Connor MJ, et al: Investigation of radiosensitivity gene signatures in cancer cell lines. PLoS One 9 e86329, 2014

32. Nilsson S, Carlsson J, Larsson B and Ponten J: Survival of irradiated glia and glioma cells studied with a new cloning technique. Int J Radiat Biol Relat Stud Phys Chem Med 37: 267-279, 1980.

33. Deschavanne PJ, Fertil B, Malaise EP and Lachet B Radiosensitivity and repair of radiation damage in human HF19 fibroblasts. Int J Radiat Biol Relat Stud Phys Chem Med 38: 167-177, 1980.

34. Carrie C, Muracciole X, Gomez F, Habrand JL, Benhassel M, Mege M, Mahé M, Quetin P, Maire JP, Soum F, et al Conformal radiotherapy, reduced boost volume, hyperfractionated radiotherapy, and online quality control in standard-risk medulloblastoma without chemotherapy: Results of the French M-SFOP 98 protocol. Int J Radiat Oncol Biol Phys 63: 711-716, 2005.

35. Hall E and Giaccia A: Radiobiology for the Radiologist 7th edition. Lippincott, Williams \& Wilkins, Philadelphia, USA, 2012 .
36. Fernandez-Capetillo O,Lee A,Nussenzweig M and Nussenzweig A: H2AX: The histone guardian of the genome. DNA Repair (Amst) 3: 959-967, 2004

37. Westhoff MA, Kandenwein JA, Karl S, Vellanki SH, Braun V, Eramo A, Antoniadis G, Debatin KM, Fulda S, et al: The pyridinylfuranopyrimidine inhibitor, PI-103, chemosensitizes glioblastoma cells for apoptosis by inhibiting DNA repair. Oncogene 28: 3586-3596, 2009.

38. Westhoff MA, Faham N, Marx D, Nonnenmacher L, Jennewein C, Enzenmüller S, Gonzalez P, Fulda S and Debatin KM: Sequential Dosing in Chemosensitization: Targeting the PI3K/Akt/mTOR Pathway in Neuroblastoma. PLoS One 8: e83128, 2013.

39. Tsutsumi $K$, Tsuda M, Yazawa N, Nakamura H, Ishihara $S$, Haga H, Yasuda M, Yamazaki R, Shirato H, Kawaguchi H, et al: Increased motility and invasiveness in tumor cells that survive 10Gy irradiation. Cell Struct Funct 34: 89-96, 2009.

40. Jung JW, Hwang SY, Hwang JS, Oh ES, Park S and Han IO: Ionising radiation induces changes associated with epithelialmesenchymal transdifferentiation and increased cell motility of A549 lung epithelial cells. Eur J Cancer 43: 1214-1224, 2007.

41. Furnari FB, Fenton T, Bachoo RM, Mukasa A, Stommel JM, Stegh A, Hahn WC, Ligon KL, Louis DN, Brennan C, et al: Malignant astrocytic glioma: Genetics, biology, and paths to treatment. Genes Dev 21: 2683-2710, 2007.

42. CBTRUS: Central Brain Tumor Registry of the US Statistical Report: 2009-2010 CBTRUS Statistical Report Primary: Brain and Central Nervous System Tumors Diagnosed in the United States in 2004-2006. Central Brain Tumor Registry of the US, Hinsdale, IL, pp1-61, 2010.

43. Robert M and Wastie M: Glioblastoma multiforme: a rare manifestation of extensive liver and bone metastases. Biomed Imaging Interv J 4: e3, 2008.

44. Beauchesne P: Extra-neural metastases of malignant gliomas: Myth or reality? Cancers 3: 461, 2011.

45. Rao JS: Molecular mechanisms of glioma invasiveness: The role of proteases. Nat Rev Cancer 3: 489-501, 2003.

46. Snuderl M, Fazlollahi L, Le LP, Nitta M, Zhelyazkova BH, Davidson CJ, Akhavanfard S, Cahill DP, Aldape KD, Betensky RA, et al: Mosaic amplification of multiple receptor tyrosine kinase genes in glioblastoma. Cancer Cell 20: 810-817, 2011.

47. Ene CI and Fine HA: Many tumors in one: a daunting therapeutic prospect. Cancer Cell 20: 695-697, 2011.

48. Wolburg H, Noell S, Fallier-Becker P, Mack AF and WolburgBuchholz K: The disturbed blood-brain barrier in human glioblastoma. Mol Aspects Med 33: 579-589, 2012.

49. Salphati L, Shahidi-Latham S, Quiason C, Barck K, Nishimura M, Alicke B, Pang J, Carano RA, Olivero AG and Phillips HS: Distribution of the phosphatidylinositol 3-kinase inhibitors Pictilisib (GDC-0941) and GNE-317 in U87 and GS2 intracranial glioblastoma models-assessment by matrix-assisted laser desorption ionization imaging. Drug Metab Dispos 42: 1110-1116, 2014

50. Drake CG, Pfalzner PM and Linell EA: Intracavitary irradiation of malignant brain tumours. J Neurosurg 20: 428-434, 1963.

51. Peirce CB: The efficacy of radiation therapy in the treatment of tumors of the brain and brain stem. Clin Neurosurg 10: 195-211, 1964.

52. Walker MD, Strike TA and Sheline GE: An analysis of doseeffect relationship in the radiotherapy of malignant gliomas. Int $\mathbf{J}$ Radiat Oncol Biol Phys 5: 1725-1731, 1979.

53. Salazar OM, Philip Rubin MD, Feldstein ML and Pizzutiello R: High dose radiation therapy in the treatment of malignant gliomas: Final Report. Int J Radiat Oncol Biol Phys 5: 1733-1740, 1979.

54. Sheline GE: Radiotherapy for high grade gliomas. Int J Radiat Oncol Biol Phys 18: 793-803, 1990.

55. Djuzenova CS, Guttler T, Berger S, Katzer A and Flentje M: Differential response of human glioblastoma cell lines to combined camptothecin and ionizing radiation treatment. Cancer Biol Ther 7: 364-373, 2008.

56. Vellanki SH, Grabrucker A, Liebau S, Proepper C, Eramo A, Braun V, Boeckers T, Debatin KM and Fulda S: Small-molecule XIAP inhibitors enhance gamma-irradiation-induced apoptosis in glioblastoma. Neoplasia 11: 743-752, 2009.

57. Berger R, Jennewein C, Marschall V, Karl S, Cristofanon S, Wagner L, Vellanki SH, Hehlgans S, Rödel F, Debatin KM, et al: $\mathrm{NF}-\kappa \mathrm{B}$ is required for Smac mimetic-mediated sensitization of glioblastoma cells for $\gamma$-irradiation-induced apoptosis. Mol Cancer Ther 10: 1867-1875, 2011. 
58. Ma H, Rao L, Wang HL, Mao ZW, Lei RH, Yang ZY, Qing H and Deng YL: Transcriptome analysis of glioma cells for the dynamic response to $\gamma$-irradiation and dual regulation of apoptosis genes: A new insight into radiotherapy for glioblastomas. Cell Death Dis 4: e895, 2013.

59. Li N, Maly DJ, Chanthery YH, Sirkis DW, Nakamura JL, Berger MS, James CD, Shokat KM, Weiss WA and Persson AI: Radiotherapy followed by aurora kinase inhibition targets tumorpropagating cells in human glioblastoma. Mol Cancer Ther 14: $419-428,2015$

60. Setua S, Ouberai M, Piccirillo SG, Watts C and Welland M Cisplatin-tethered gold nanospheres for multimodal chemoradiotherapy of glioblastoma. Nanoscale 6: 10865-10873, 2014.

61. Kuger S, Flentje M and Djuzenova CS: Simultaneous perturbation of the MAPK and the PI3K/mTOR pathways does not lead to increased radiosensitization. Radiat Oncol 10: 214, 2015.

62. Balbous A, Cortes U, Guilloteau K, Rivet P, Pinel B, Duchesne M, Godet J, Boissonnade O, Wager M, Bensadoun RJ, et al: A radiosensitizing effect of RAD51 inhibition in glioblastoma stem-like cells. BMC Cancer 16: 604, 2016.
63. Grunert M, Kassubek R, Danz B, Klemenz B, Hasslacher S, Stroh S, Schneele L, Langhans J, Ströbele S, Barry SE, et al: Radiation and Brain Tumors: An Overview. Crit Rev Oncog 23: 119-138, 2018.

64. Karagiannis GS, Pastoriza JM, Wang Y, Harney AS, Entenberg D, Pignatelli J, Sharma VP, Xue EA, Cheng E, D'Alfonso TM, et al: Neoadjuvant chemotherapy induces breast cancer metastasis through a TMEM-mediated mechanism. Sci Transl Med 9: eaan0026, 2017.

65. Giese A: Glioma invasion - pattern of dissemination by mechanisms of invasion and surgical intervention, pattern of gene expression and its regulatory control by tumorsuppressor $\mathrm{p} 53$ and proto-oncogene ETS-1. Acta Neurochir Suppl 88: 153-162, 2003.

66. Hatzikirou H, Basanta D, Simon M, Schaller K and Deutsch A: 'Go or grow': The key to the emergence of invasion in tumour progression? Math Med Biol 29: 49-65, 2012.

This work is licensed under a Creative Commons Attribution-NonCommercial-NoDerivatives 4.0 International (CC BY-NC-ND 4.0) License. 